\title{
Public Support for Government Responses Against COVID-19: Assessing Levels and Predictors in Eight Western Democracies During 2020
}

\author{
Frederik Jørgensen ${ }^{1}$, Alexander Bor ${ }^{1}$, Marie Fly Lindholt ${ }^{1}$, and Michael Bang Petersen ${ }^{1^{*}}$ \\ ${ }^{1}$ Department of Political Science, Aarhus University, Denmark \\ ${ }^{*}$ Corresponding author: michael@ps.au.dk
}

June 9, 2021

\begin{abstract}
To halt the spread of COVID-19 governments have engaged in policies that are both economically costly and involve infringements of individual rights. In democratic countries, these policy responses have elicited significant debate but we know little about the extent to which the responses are supported or opposed by the broader public. This article investigates how citizens across eight Western democracies evaluate the specific policies imposed by their governments to contain the COVID-19 pandemic. We rely on large-scale, longitudinal surveys that are reflective of the national populations (total $\mathrm{N}=124,062$ ). On this basis, we investigate how pandemic-specific and broader political attitudes correlate with support for government responses during a significant part of 2020, a period marked by pandemic restrictions in all the countries. We find medium to high levels of support for the government's responses in all eight countries. Beyond the regular voters of the government, support is driven by individuals high in interpersonal trust and self-assessed knowledge about COVID19. This may suggest that halting the spread of COVID-19 is viewed as a collective action problem and mobilizes support from those knowing how to act and trusting others to act similarly.
\end{abstract}

Keywords: COVID-19; Policy Support; Voting; Interpersonal Trust; Collective Action

Published in West European Politics. Please reference the published version:

https://doi.org/10.1080/01402382.2021.1925821 
The COVID-19 pandemic has put democratic governments in an uncomfortable position: to halt the spread of the coronavirus they have introduced stringent policies including mandating quarantines, stay at home orders, closures of public institutions and private business (Lewnard and Lo 2020). These measures entail several costs. First, they involve some violations of citizens' democratic and civic rights (Timotijevic 2020) such as the right to assembly. Second, they have negative economic consequences (Goodell 2020). Unemployment has risen to unprecedented heights in several countries, and sectors in the service industry from small bars to major airlines are struggling financially. Finally, they involve adverse health consequences in the form of psychosocial costs from increased isolation (Clemmensen, Petersen and Sørensen 2020) as well as a downproritization of other illnesses.

In light of these costs, it is key for governments to generate public support for their measures. The interventions against COVID-19 require significant changes in the habits of ordinary people and, especially, in private areas of life related to hygiene and social interaction, which are difficult to monitor. Widespread support are thus key for compliance (Tyler 2006). Generating the required compliance is complicated by not only the costs of the interventions but also the fact that governments are maneuvering in a situation characterized by both high stakes in terms of potential loss of lives and high uncertainty due to the novel nature of the COVID-19 disease. As a consequence, it is not surprising that the policies have been met with opposition from some members of the public. The United States has witnessed vocal opposition against mandatory physical distancing measures; Serbia experienced riots in response to the announcement of a lockdown; and more peaceful protests have taken place also in other countries, such as Germany, Denmark and the Netherlands (for an attempted list of COVID-19-related protests, see (Wikipedia 2020).

On this background, this article asks two questions: First, to what extent is the governmentspecific responses against COVID-19 across Western democracies supported by their general publics? Are people in general opposed to or supportive of their government's specific handling of the COVID-19 pandemic? Second, what explains variation in evaluations? While the severity of the pandemic and the exact nature of interventions are important macro-variables, we aim to provide a comprehensive assessment of the role of individual-level variables: Which individuals are more likely to oppose the policies of their government and who are more likely to support 
them? We assess a traditional range of sociodemographic and political cleavages that the interventions may activate and, on the basis of recent research in health-related attitudes, a range of measures that may be particularly relevant in relation to COVID-19. In addition, we utilize our findings at the individual level to shed light on how changes in individual-level factors shapes support over time and across countries.

This article seeks to answer these questions relying on large-scale online surveys from eight Western democracies, Denmark, France, Germany, Hungary, Italy, United Kingdom, United States and Sweden. Our data collection started just within two weeks after the first Western country, Italy, went into lockdown and collected large, quota sampled cross-sectional samples in each country for the remainder of 2020. These eight countries all had distinct epidemic trajectories and differed in the stringency of their responses, although all government responses involved some degree of stringency. Hence, we are able to examine how specific individual-level characteristics shape support for the government responses across a variety of contexts. In addition, we use the fact that the data collection is conducted over time and across countries to examine the role of both within- and between-country variation in context and to conduct analyses with higher degrees of causal leverage.

Whereas previous research has sought to understand who supports stringent responses against COVID-19 or who are most motivated to comply with stringent restrictions (Van Bavel et al. 2020; Jørgensen, Bor and Petersen 2020), the present focus is instead on whether and from whom national governments during a massive crisis can foster support for the particular set of policies that each government promotes as necessary. Overall, the results show that this is indeed possible and we document relatively high support for each government's response against COVID-19. Variation in support for each government's response is only to a limited extent explained by traditional demographic cleavages, except that individuals who voted for the government in the previous national election are much more likely to be supportive of the government's response. In addition to government voters, we find that supporters are especially found among individuals who are (i) prosocial, (ii) trust others and (iii) feel knowledgeable about how to behave against COVID-19. In contrast, support is not particularly prominent among people who are disposed to feel fear and who are concerned about the COVID-19 pandemic. This may suggest that support for stringent responses is less driven by concerns for 
personal protection and more by motivations to support the government's efforts of pandemic control as a form of collective action. People beyond the government's regular voters are willing to contribute with their support if they feel they know what to do and trust that others are similarly motivated.

\section{Who will support their government's response against COVID- $19 ?$}

While the exact nature of government responses varies across countries and times, all Western countries have used policies that put significant limitations on citizens since the start of the COVID-19 pandemic. The primary benefit of these policies is in the form of protection against infections. Their primary costs are economic in nature as well as adverse health consequences from social isolation (Clemmensen, Petersen and Sørensen 2020). These costs and benefits are differentially distributed across demographic groups and, hence, the COVID-19 crisis may tap into pre-existing demographic cleavages.

In assessing the potential costs and benefits of the responses, age is a key sociodemographic characteristic. The mortality rates of the corona-virus has a very steep age gradient (Promislow 2020 ) and, hence, stringent policies will, all else equal, have higher health benefits for the elderly. Furthermore, the disruption of social interaction in public (e.g., in the form of closing bars and night clubs) is likely to entail less social costs for the elderly than for younger, more outgoing individuals.

Socioeconomic factors are also potential explanatory factors when understanding support for the varying government responses. The COVID-19 pandemic is a "total crisis" in the sense that it impacts every area of society and, as such, stringent policies are likely to exacerbate existing socioeconomic inequalities (Blundell et al. 2020). Thus, in addition to age, it is possible that support for the government responses falls along socioeconomic cleavages related to employment status and education. Specifically, we expect those who are more economically vulnerable to be less supportive of the stringent responses implemented by governments. In this way, interventions against the corona virus may activate existing sociodemographic cleavages and further polarization.

In addition to demographic cleavages, the stringent measures against COVID-19 potentially 
taps into more directly political cleavages. The most obviously relevant cleavage relates to prior voting behavior. Voters tend to support the policies of their preferred party (Bolsen, Druckman and Cook 2014) and we should expect government supporters and opposition supporters to differ in their support during the COVID-19 pandemic as well. Government voters are expected to be substantially more supportive of the government's interventions. Another relevant factor is political ideology, although the direction of any association is not a priori clear. On the one hand, people on the right are more sensitive to health crises, and exposure to health crises makes people a bit more conservative (Beall, Hofer and Schaller 2016). On the other hand, many stringent policies against COVID-19 can be seen as infringements of basic freedom rights including the pursuit of prosperity, something that is often more valued among individuals on the right (Tetlock 1986). Finally, it is relevant to consider the more recent political cleavage related to right-wing populism. Again, it is possible argue for opposite predictions. On the one hand, populists may be less supportive of government interventions because of the link between populism and scientific skepticism (Mede and Schäfer 2020). On the other hand, an integral component of populism is support of strong leadership styles (Mudde and Kaltwasser 2014), which may make populists more supportive of the rapid and significant interventions executed in many countries.

At the same time, prior research suggest that crisis situations such as pandemics sometimes overcome traditional political cleavages. Indeed, in 2008, a study on the avian flu, Paek et al. (2008) found broad-based support for a wide-range of stringent responses to a flu epidemic. Furthermore, Bol et al. (2020) show in an interrupted time series analysis that lockdown measures during the COVID-19 pandemic had a positive impact on support for incumbent parties. Finally, Rieger and Wang (2020) rely on a large convenience sample with respondents from 57 countries to show that across the globe, distrust in the governments is caused mostly by a lack of action.

To understand the motivations underlying support for the government's particular response during the COVID-19 pandemic specifically, it is relevant to consider how the psychological literature has identified two distinct types of reactions to disease-related threats. On the one hand, a large psychological literature shows that feelings of threats including disease threats activate strong support for policies that are framed as protective (Kam and Estes 2016). On 
the other hand, health threats have been found to not just activate fear but to also activate compassion towards those affected (Steinkopf 2017). Because diseases are typically viewed as random accidents, the victims are seen as morally deserving of public help (Jensen and Petersen 2017). In the context of COVID-19, for example, prior research suggest that individuals higher in empathy are more likely to follow the advice of health authorities (Pfattheicher et al. 2020), as are those fearful of the virus (Jørgensen, Bor and Petersen 2020). In tandem, this implies that government responses may be supported from two, rather different, motivations: A fear-based motivation to protect the self and a prosocial motivation to protect others.

In order to understand who are most likely to support government responses from either of these motivations, we consider two sets of variables: Personality dispositions and more proximate attitudinal factors. There is increased evidence that political behaviors and attitudes reflect more durable individual differences in how people approach the world as reflected in their personality (Gerber et al. 2011; Mondak 2010). Following extant research, we utilize the Big Five inventory that carves human personality variation into five dimension: Openness to New Experiences, Conscientiousness, Extraversion, Agreeableness and Neuroticism (Gerber et al. 2011; Mondak 2010).

Neuroticism is the key personality trait related to stress, worry and fear and, hence, we expect that individuals high in neuroticism are more likely to support government interventions against COVID-19. Agreeableness is the key personality trait related to prosociality and cooperativeness and, hence, we expect agreeableness to also increase support for interventions. The other personality dimensions are not directly related to the two highlighted motivations but could potentially also shape support for the government response. Extraverts may find the disruption of social interaction more costly; those high in conscientiousness could be more motivated to endorse stringent policies that impose order on everyday lives; and those high in openness may be better able to adjust to the novel situation of, for example, a lockdown.

In addition to these personality dispositions, it is also relevant to consider more proximate attitudinal factors. A predictor of fear-based support for stringent government responses would be egotropic, or personal, fear of the coronavirus. A predictor of a prosocial support for government responses against COVID-19 would be sociotropic, or societal, concern about the coronavirus. Consistent with the argument that both types of worries can generate support for 
lockdowns during the COVID-19 pandemic, prior research on general health behavior suggest that they are both related to the uptake of protective measures ( Maddux and Rogers 1983). Furthermore, theoretical work has suggested that one particularly relevant measure of prosocial motivations to support COVID-19 measures is interpersonal trust. Hence, interpersonal trust is a key predictor of cooperativeness and willingness to contribute to collective action (Ostrom 1998). Epidemic control can be seen as a collective action problem where collective effort is required but also challenged by the potential existence of free-riders $(\overline{J o h n s o n}$ et al. $\mid 2020)$. In such contexts, it is crucial for contributions to the collective project that contributors trust others to contribute as well. In addition to personal and societal concerns, we therefore also assess the effects of interpersonal trust.

Finally, we want to raise the possibility that an ostensibly less psychologically complex factor could be central for understanding support for government interventions: Knowledge about the coronavirus and protective behaviors. Stringent policies have emerged as the key international remedy to counter the spread of the pandemic, advocated by both national governments, WHO and independent researchers (Lewnard and Lo 2020). Furthermore, this information has been broadcasted with unprecedented intensity in media across the world. If we find little opposition to the governments' responses it may reflect that people have acquired the knowledge that some degree of stringency is internationally recommended against the virus. Consistent with this, prior work suggest that knowledge-related measures have been crucial determinants of protective behavior during earlier pandemics (Maddux and Rogers 1983; Rippetoe and Rogers 1987) and recent findings highlight that a belief that one is well-informed about COVID-19 constitutes one of the best predictors of compliance with physical distancing policies (Jørgensen, Bor and Petersen 2020$)$.

\section{Materials and methods}

\section{Data}

Since the first wave of the COVID-19 pandemic, we have been fielding online surveys reflective of national populations in eight countries: Denmark, France, Germany, Hungary, Italy, Sweden, the United Kingdom (UK), and the United States of America (USA). ${ }^{1}$

In each round of data collection, we sampled approximately 500 respondents from the pop- 
ulation of eligible voters in each country. Our total sample size is $\mathrm{N}=124,062$. Quotas were used to ensure that samples resemble population margins on age, gender, and geography. After completing the survey, panelists in the sampling frame could not be re-sampled for a month. After this period, panelists became eligible to participate again, which means our data contains repeated observation from a subset of respondents. Below, we explain how this feature of our data is exploited to increase the internal validity of our tests.

Data collection started in the middle of March. While data collection is still ongoing as of January 2021, we rely on data until November 7, 2020 for this article (for country specific start and end dates and sample sizes see Table OA1). Hence, our data offers insights from all three phases of the pandemic so far: (1) the first wave in the spring of 2020, characterized by high and poorly controlled infection numbers and relatively high casualties (except in Hungary and Denmark); (2) the summer, witnessing successful efforts to contain the virus in most countries, although with significant variation; and (3) the second wave of the pandemic in the fall, when infections surged but, again, with large variation in how well or poorly countries managed this challenge.

It should be noted that some parts of the questionnaire has been changed two times - on April 8 and on September 13 - thereby we rely on three versions of the survey. While these changes were small overall, they imply that some variables were observed only in the first version, whereas others are available only in the second or third version.

\section{Measures}

We measure support for the government response using a survey question asked in the context of a question-battery, where respondents were first asked: To what extent do you agree or disagree with the following statements? Then, they answered a number of statements, including our outcome "... the government conducts the policy necessary to handle the Corona virus". Respondents answered the question on a 5-point scale from "disagree completely" to "agree completely".

We group our predictors of support into four categories, including demographics, political correlates, personality traits, and attitudinal correlates.

To assess the role of sociodemographic cleavages we include sex, age, and education as 
correlates in our models. Sex is an indicator variable ( 0 for males; 1 for females). Age is a continuous variable asking respondents how old they are. Education is an indicator variable based on the internationally comparable ISCED-scale ( 0 for non-tertiary education; 1 for tertiary education). Note, that the demographics were measured for the entire survey period.

To assess the role of political divides in shaping support, we include three political variables. First, an indicator for voting for the prime minister's party at the last first order election (this indicator was measured for the entire survey period). Second, a standard left-right selfplacement scale ranging from 1 (left) to 10 (right). This left-right scale was only included in the third survey version (from September 13 and onwards). Third, we also include a measure of political populism, focusing on support for strong leaders (Mudde and Kaltwasser 2014): To what extent do you agree with the following statement ... Our country needs a strong leader right now. Respondents answered this question on a scale from "completely agree" to "completely disagree". This question was asked from the second survey version and onwards (that is, from April 9).

For the personality trait variables, we rely on the standard measures of the big five personality traits: Neuroticism, extraversion, openness, agreeableness, and conscientiousness. These were tracked in the context of a previosuly validated 15-item battery (Hahn, Gottschling and Spinath 2012). For each item, respondents answered on 5-point scales from "disagree completely" to "agree completely". Respondents saw the initial text "I see myself as a person who..." and then read the 15 trait statements. The items form scales with alpha values ranging from $\alpha=0.44$ (conscientiousness) to $\alpha=0.77$ (extraversion). For details on the trait statements and $\alpha$ levels, please see Section A.2 of the Online Appendix (OA for short in the following). The personality trait variables were only measured in the first version of the survey (until April $8)$.

The attitudinal correlates include a measure of personal worry, a measure of societal worry, a knowledge measure, and a measure of interpersonal trust. In the first version of the survey (until April 8), we asked two questions about personal fear: To what degree are you concerned about the consequences of the Corona virus ... (1) for yourself and (2) your family? In the second version (after April 8), we collapsed the question asking: To what degree are you concerned about the consequences of the Corona virus for yourself and your family? Respondents answered 
these questions on 4-point scales ranging from "not at all" to "to a high degree". For the first version, we average over the two worry items to form a single measure of personal worry, while for the second version personal worry is captured by the single question.

Worry that stems from societal concerns is measured with the question "To what degree are you concerned about the consequences of the Corona virus ... for your country". Respondents similarly answered this question on a 4-point scale ranging from "not at all" to "to a high degree".

To tap self-assessed knowledge about behavior during the coronavirus pandemic, we utilize a question that asks: To what degree do you feel that you know enough about what you as a citizen should do in relation to the Corona virus? Respondents answered this question on a 4-point scale from "not at all" to "to a high degree".

We use a standard question to measure interpersonal trust: "Do you think that most people by and large are to be trusted, or that you cannot be too careful when it comes to other people?". Respondents answered this question on a 10-point scale.

All predictors are scaled from 0-1 in the analyses below. Table 1 reports the descriptive statistics for all the above correlates in our overall sample. Moreover, Figure OA1 gives an overview of all bivariate correlations between the variables in Table 1 .

\section{Statistical analysis}

We conduct three different sets of statistical analyses. First, our main analyses aim to identify the most important correlates of support at the individual level. Second, to gauge causality, we utilize the fact that the data have a panel component. Specifically, 19,370 individuals have been observed at least twice during the survey period for a total of 54,534 observations. In this panel sample, we estimate the causal impact of the attitudinal correlates (which are subject to change over time as opposed to the other correlates) using a two-way fixed effects estimator that applies individual-level as well as time fixed effects. Third, we aggregate our outcome and predictors at the country level to analyze how well the correlates explain the observed country-level differences in support.

For the main analyses of support for the government's response, we develop four models. As described, these models differ in their number of observations as some variables are not available 
Table 1: Descriptive statistics

\begin{tabular}{lccccc}
\hline \hline & Mean & SD & Min & Max & $\mathrm{N}$ \\
\hline $\begin{array}{l}\text { Outcome } \\
\text { Support for response }\end{array}$ & 0.62 & 0.33 & 0.00 & 1.00 & 121,375 \\
$\begin{array}{l}\text { Demographics } \\
\text { Sex (female) }\end{array}$ & 0.52 & 0.50 & 0.00 & 1.00 & 124,062 \\
Age & 0.29 & 0.17 & 0.00 & 1.00 & 123,270 \\
Tertiary education & 0.50 & 0.50 & 0.00 & 1.00 & 124,062 \\
Political correlates & & & & & \\
Government vote & 0.29 & 0.46 & 0.00 & 1.00 & 124,062 \\
Left-right self-placement & 0.49 & 0.25 & 0.00 & 1.00 & 12,719 \\
Strong leader preference & 0.76 & 0.28 & 0.00 & 1.00 & 91,867 \\
Attitudinal correlates & & & & & \\
Covid personal worry & 0.66 & 0.28 & 0.00 & 1.00 & 124,060 \\
Covid societal worry & 0.70 & 0.24 & 0.00 & 1.00 & 124,060 \\
Covid knowledge & 0.80 & 0.22 & 0.00 & 1.00 & 121,268 \\
Interpersonal trust & 0.48 & 0.28 & 0.00 & 1.00 & 124,061 \\
Personality traits & & & & & \\
Neuroticism & 0.42 & 0.23 & 0.00 & 1.00 & 18,689 \\
Extraversion & 0.58 & 0.24 & 0.00 & 1.00 & 18,689 \\
openness & 0.63 & 0.21 & 0.00 & 1.00 & 18,692 \\
Agreeableness & 0.70 & 0.17 & 0.00 & 1.00 & 18,692 \\
conscientiousness & 0.68 & 0.16 & 0.00 & 1.00 & 18,692 \\
\hline \hline
\end{tabular}

Notes: Higher values correspond to higher levels on each variable.

over the entire time period. The first model includes our battery of demographic correlates and the government vote indicator. These variables were all observed from March 19 and onward and the model includes 120,657 observations across the countries in our sample. Model 2-4, in turn, add variables to this baseline model. The second model adds left-right self-placement as well as strong leader preference. This model of political variables includes 12,130 observations. The third model is a personality trait model that adds the big five personality traits. These personality traits were only observed until March 31 and the model includes 18,116 observations. Finally, our fourth model adds the attitudinal variables, which were observed throughout the period. This fourth model includes 117,915 observations.

For this first set of analyses a methodological challenge is the clustering due to multiple countries and rounds of data. We rely on multilevel modelling to address this challenge. Specifically, for the estimates in the main text, we include varying intercepts for both countries and time (i.e., survey round) into the models. Moreover, we also include varying slopes by country to estimate the heterogeneity in the associations between our independent and dependent 
variables. $^{2}$

For our panel sample, we estimate the causal impact of a change in each of our attitudinal variables on support using two-way fixed effects models that applies individual-level and time fixed effects. As consequence, we are able to control for stable individual differences in support by only using within-individual variation in support and the attitudinal correlates. In other words, rather than estimating average support among individuals with high versus low levels of knowledge, we estimate the change in support corresponding to a change in knowledge within the same individual. The time fixed effects account for potential time trends in support. This two-way fixed effects estimator provides and unbiased estimate of the causal impact of our attitudinal variables on the assumption of parallel trends (that we assess below). Under this assumption, the double fixed effects estimator is a rigorous strategy for identifying causal effects in observational data (Angrist and Pischke 2008). To correct for clustering, we cluster standard errors by individual and time.

For our country-level analyses, we aggregate our support outcome as well as all the predictors. This enables us to assess how well the correlates explain the difference in support across countries. As we detail below, these models also include a measure of the stringency of the government's policy and a measure of the severity of the epidemic.

Finally, it should be noted that for the individual-level analyses the size of the estimated coefficients reported below reflects the change in support when we compare individuals at the minimum and maximum values, respectively, of each of the correlates. For the country-level analyses, the estimated changes in the support outcome reflect increases of two standard deviations in each of the predictors. We use this approach to avoid "extreme" comparisons especially with regard to the measures of policy stringency and epidemic severity, which both vary substantially across countries. All reported p-values are based on two-sided tests.

\section{Results}

\section{Individual-level correlates}

We begin by assessing the distribution of support for the government responses by country (Figure 1). Horizontal boxes show the 25th-75th percentile of the distribution. The white crosses and bars display mean and median values, respectively, while the whiskers show minimum and 
maximum support levels. We observe the largest degree of support in Denmark (0.8) and in Germany (0.7). In the UK and Italy, we observe a moderate level of support of about 0.6. In the remaining countries, the outcome is relatively evenly distributed around the mean and median value of support ranging between 0.56 in Sweden and 0.49 in France.

Figure 1: Support for Government Responses
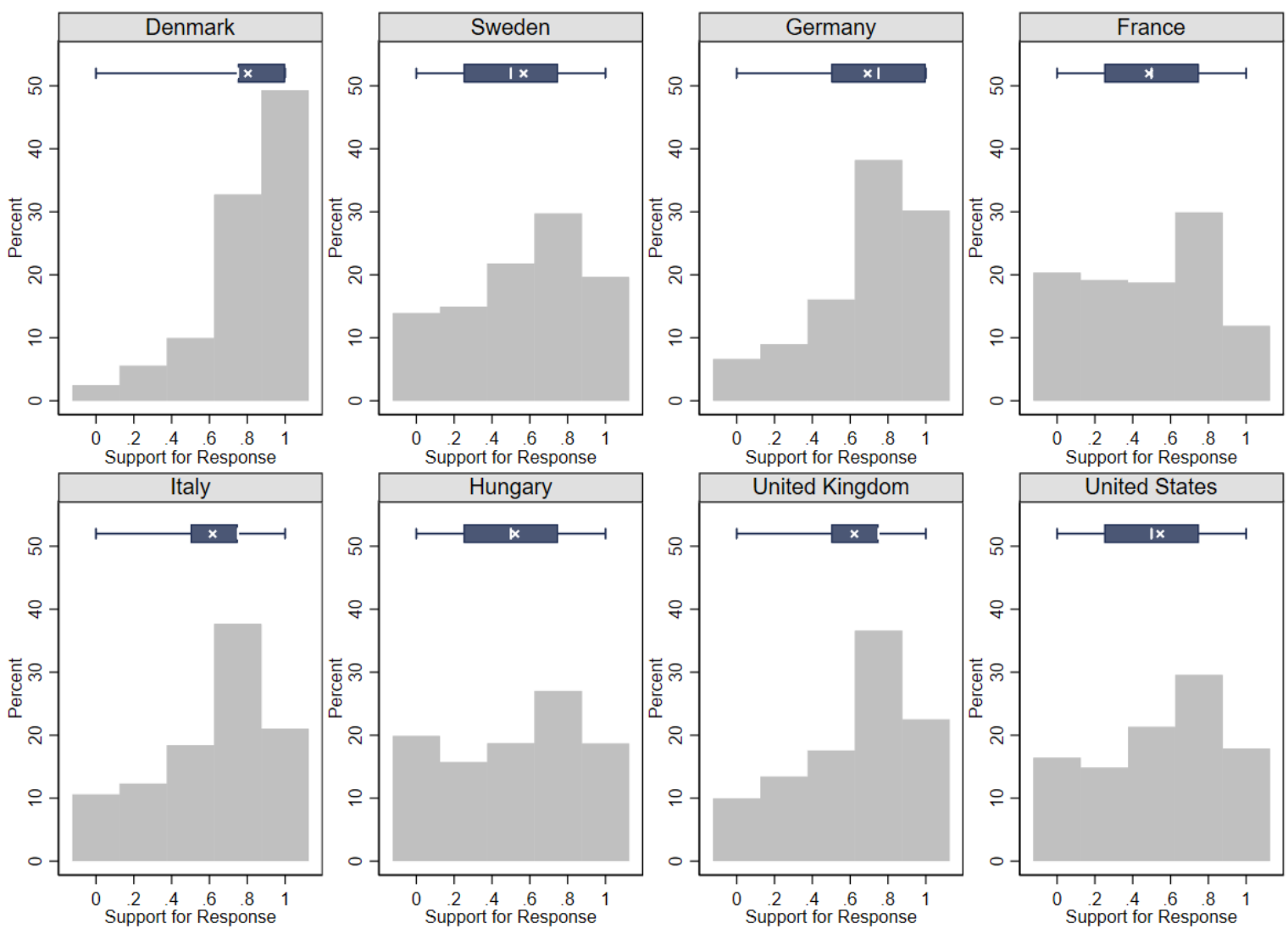

Note: Histograms: display the distribution of support for government responses, by country. Boxplots: boxes hold the 25th-75th percentile, white bars are median values, white crosses are mean values, while whiskers are minimum and maximum values. Distributions are based on the benchmark sample.

On this basis, we turn towards understanding the individual-level predictors of support. Figure 2 shows the estimated overall partial correlations between government support and individual-level predictors based on our benchmark model, where we partially pool data across the countries. The left panel displays the results from the baseline model. The second panel adds the additional political correlates. The third panel adds the personality trait variables. Finally, the fourth panel displays the attitudinal correlates model. Note that the correlation in Figure 2 reflects the average correlations between support and each of the predictors. Figure 3 shows the country-specific correlations. 
Focusing on demographics, we generally observe a striking absence of demographic heterogeneity in respondents' support for their government's response. Hence, across the models neither sex, age, nor education statistically significantly predict support for COVID-19 response.

Moving to the political variables, it is clear that voting for the governing party at the last national first order election substantively and statistically significantly predicts response support, across all models. In the baseline model, respondents who report that they voted for the governing party are about 20 percentage points more positive about the government's response compared to respondents who reported that they did not vote for the party $\left(\beta_{\text {Governmentvote }}=\right.$ $0.195, p<0.001)$. In contrast, the second panel shows that neither left-right placement nor a preference for a strong leader correlate statistically significantly with support. In terms of traditional demographic and political cleavages, COVID-19 interventions mainly seem to tap into the one between government and opposition.

Figure 2: Support for response, benchmark correlations

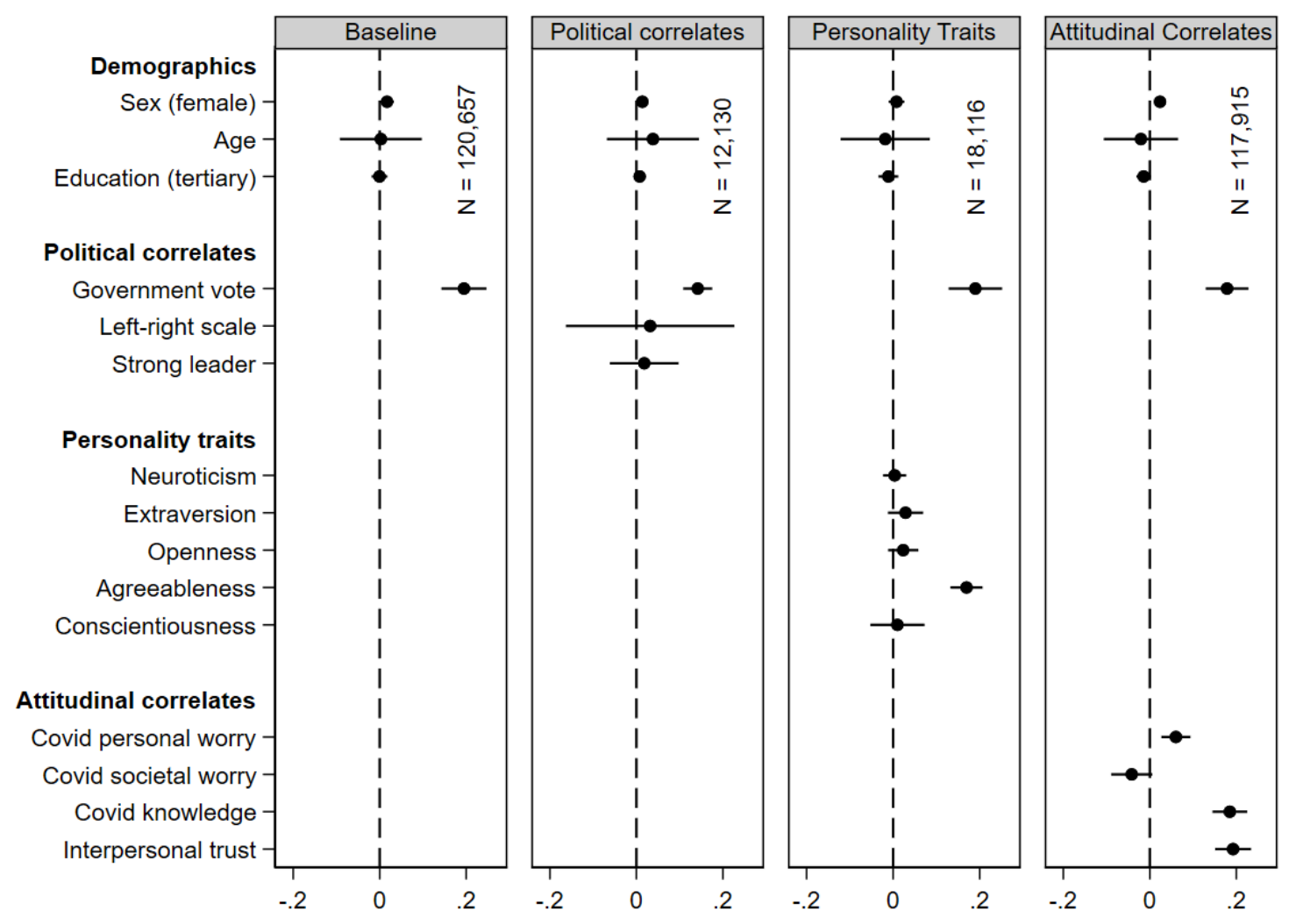

Note: Estimated correlations from our benchmark model. First panel: Baseline model. Second panel: Adds Left-right self-placement and preference for a strong leader. Third panel: Adds personality traits (observed only until March 31). Right panel: Adds attitudinal correlates (for Fance we only have observations from April 9 and onwards). Filled black circles are the estimated correlations. Horizontal bars are the associated $95 \%$ confidence intervals. The outcome is scaled 0-1 such that coefficients correspond to percentage point changes. 
Among the personality trait variables, agreeableness stands out as the most important predictor of support. Thus, agreeableness positively predicts support in the personality traits model. In particular, we see that the most agreeable evaluate their government's response about 17 percentage points more favorably compared to the least agreeable $\left(\beta_{\text {agreeableness }}=\right.$ $0.17, p<0.0001)$. This is consistent with the argument that a prosocial motivation increases support for interventions against COVID-19. None of the remaining personality traits statistically significantly correlate with support.

Regarding the attitudinal variables, it is clear that most variables, albeit to varying degrees, predict support. Personal worry moderately predicts support: Respondents who feel personally worried are about 6 percentage points more positive about the government's response compared to respondents who do not feel worried $\left(\beta_{\text {Personalworry }}=0.06, p<0.0001\right)$. This implies that fearful motivations promote support for the government's response. To the contrary, there is only limited evidence for an association between response support and worrying about the consequences of the corona virus for the society $\left(\beta_{\text {Societalworry }}=-0.042, p=0.085\right)$. Contrary to our expectations, the association is negative and insignificant according to conventional levels of statistical significance.

While societal worry is not a robust predictor of support for government interventions in our pooled sample, another key measure related to prosocial motivations, interpersonal trust, displays a strong correlation with support. Highly trusting respondents are about 19 percentage points more positive about their government's response compared to respondents who do not trust other people $\left(\beta_{\text {Interpersonaltrust }}=0.193, p<0.0001\right)$.

In addition to factors related to prosocial and fearful motivations, we also assessed the effects of self-reported knowledge about COVID-19 and associated support. Descriptively, knowledge is as important a predictor of response support as is interpersonal trust. Respondents who feel highly knowledgeable report support levels that are about 19 percentage points more positive compared to respondents who do not feel knowledgeable in relation to the corona virus $\left(\beta_{\text {knowledge }}=0.185, p<0.0001\right) .^{3}$

Overall, the above findings suggest that four correlates are particularly important for individual evaluations of government responses: Voting for the governing party at the last first-order national election, having prosocial motivations in terms of agreeable personality features, pos- 
sessing high levels of self-assessed knowledge about the corona virus, and displaying a high level of trust in other people. In addition, the results suggest that personal worry also plays some role in shaping support, while we find limited evidence for the role of societal worry.

Whereas the correlations in Figure 2 identify whether the theorized correlates overall predict response support across the countries of our sample, they simultaneously potentially mask heterogeneity in the associations across the countries. To investigate such potential heterogeneity, we extract the county-specific slopes from the models above. For each correlate, Figure 3 displays the distribution of country-specific slopes.

Figure 3: Support for response, country-specific correlations
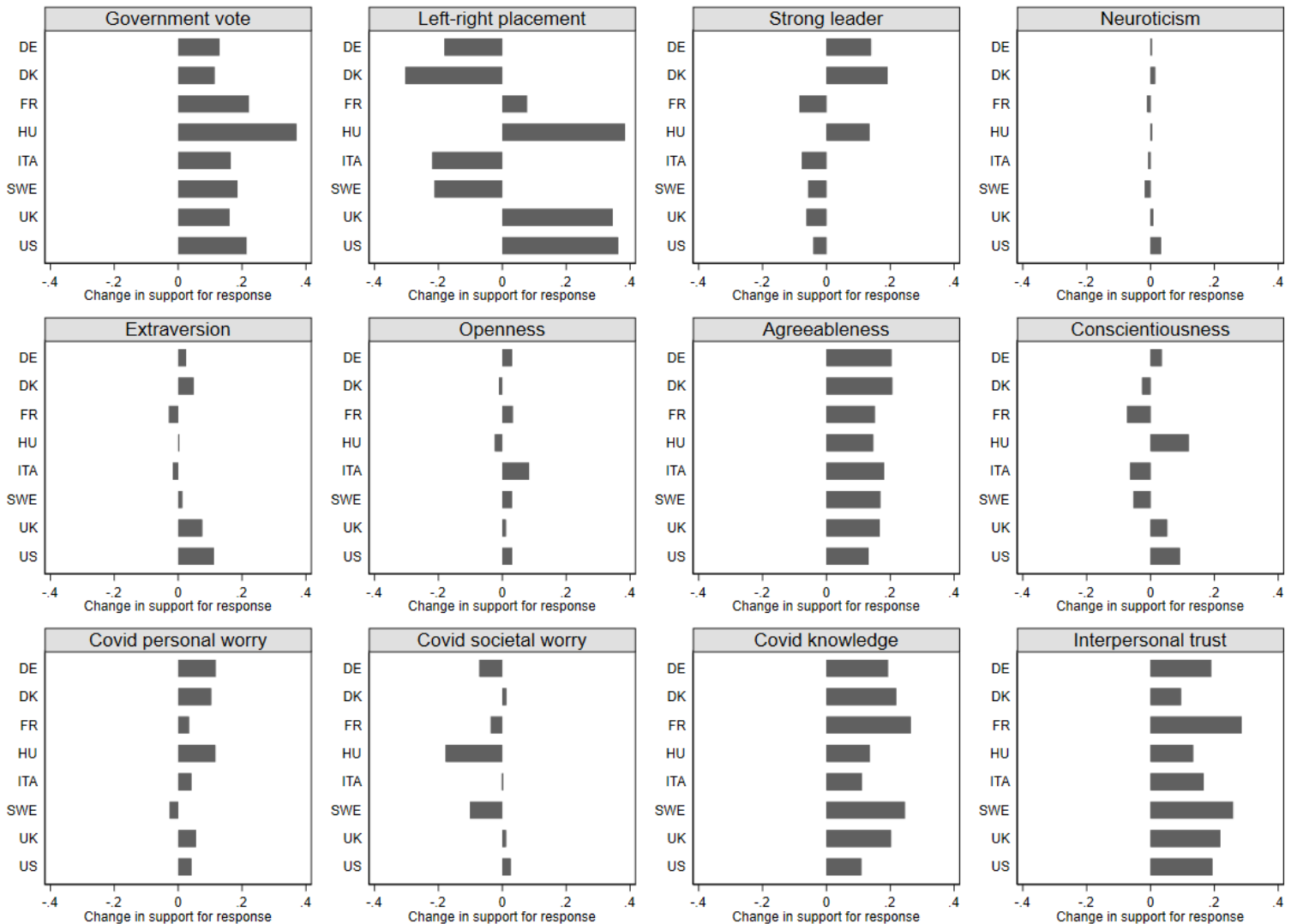

Note: Horizontal bars display the estimated country-specific associations. The estimates for government vote are based on the baseline model, the estimates for left-right self-placement and strong leader are based on the political correlates model, the personality trait estimates are based on the personality traits model, while the estimates for the psychological correlates are based on psychological model. For the psychological correlates, France is only included from April 9 and onwards because we do no observe the knowledge correlate in France before April 9.The outcome is scaled 0-1 such that coefficients correspond to percentage point changes.

Voting for the governing party at the last first-order national election consistently predicts support positively in all countries. We observe the smallest correlation between government vote and support in Denmark. Danish respondents who voted for the government, are about 11 
percentage points more positive of the government's response compared to other voters. This observation is consistent with the fact that we also observed the largest overall support for the government's response in Denmark (cf. Figure 1 above). We observe the largest correlation between government vote and support in Hungary where government voters reporting 37 percentage points more favorably about the government's response compared to other voters.

For the other political variables, the correlations vary substantially across countries, which explains the null effects observed in Figure 2. The effect of the left-right placement variable maps closely onto the ideology of the governing party: In countries with left-leaning leaders, we observe strong negative correlations; in countries with right-leaning leaders, we observe strong positive associations. Against expectations, this suggest that the stringent responses against COVID-19 does not uniformly activate right-leaning peoples' concerns about the economy or personal freedoms. Right-leaning people are willing to support interventions against COVID-19 as long as these interventions come from right-wing governments.

On the strong leader variable, we observe relatively large positive associations in Denmark, Germany, and Hungary, while the associations are negative but small in the remaining countries. This suggest that there is some potential for populist mobilization in a crisis situation like the COVID-19 pandemic but that such mobilization is not uniform across countries.

On the personality trait variables, agreeableness stands out as the most consistent predictor across all countries. Hence, we observe that agreeableness positively predict support in all countries. Moreover, the correlations are relatively stable across countries with the smallest correlation being 0.13 (USA) and the largest correlation is 0.21 (Denmark). Across all countries in the sample, we see that neuroticism do not predict support. For conscientiousness, there is no consistent pattern in the slopes. In some countries correlations are negative (with the largest correlation being 0.07 in France), in others positive (with the largest correlation being 0.12 in Hungary), while some correlations are essentially zero in some countries. For openness, there is a substantial correlation in Italy (0.08), while the correlations are small in the remaining countries. On extraversion, we see substantial correlation in the US (0.1) and the UK (0.08), while the remaining country-specific correlations are small. These inconsistent patterns explain why we observe no overall correlations between support and the personality traits - except for agreeableness - in Figure 2. 
Moving to the attitudinal factors, we observe that increased personal worry consistently predicts more support for the response in all countries but Sweden. However, there is substantial variation in how strong these correlations are. In particular, we see relative large correlations between support and personal worry in Germany (0.12), Hungary (0.12), and Denmark (0.10), while the correlations are relatively small in the remaining countries. This may be explained by the fact that the governments in these countries took relatively quick and forceful action compared to the epidemic developments in these countries (see Figure 4 below). Thus, during a pandemic, it may be important for governments to mobilize the fear of their citizens, if they seek to generate support for swift interventions prior to the accumulation of infections and deaths.

Turning to societal worry, there is no evidence in most countries of an association between support and worry about the societal consequences of the pandemic. At the same time, there is substantial negative correlations between societal worry and response support in three countries: Hungary (-0.18), Sweden (-0.10), and Germany (-0.07). To interpret these findings, it is relevant to note that Figure $\mathrm{OA} 2$ in the OA shows that the correlation between support and societal worry changes substantively over time. In Figure OA7 in the OA, this pattern is investigated in more detail. The figure shows a relatively strong positive correlation between support and societal worry in the initial lock-down phase of the pandemic in Denmark, the US, the UK, Italy, and Germany. Tn these countries the correlation drops toward 0 (and in Germany below 0) as the policy restrictions are lifted and societies re-open. To the contrary, we observe a moderately negative association throughout the period in France and strong negative correlations in Sweden (that followed a relatively less stringent strategy) and Hungary. Overall, this may suggest that societal worry facilitates support of the government's responses as long as responses are stringent (as illustrated by, e.g., Sweden compared to the other countries during lockdowns) or societies are less polarized (as illustrated by, e.g., Hungary compared to the West-European countries).

Among the attitudinal correlates, we found that knowledge and interpersonal trust on average were the strongest predictors of response evaluations across the countries. The analyses of the country-specific slopes corroborate this conclusion. Hence, across all countries in the sample, we see that increased knowledge as well as increased interpersonal trust substantively predicts higher levels of support. On knowledge, we observe the largest correlation in France where respondents who feel highly knowledgeable are 26 percentage points more supportive of 
their government's response compared to respondents who do not feel knowledgeable. We see the smallest correlation in the US with the most knowledgeable reporting that they are about 11 percentage points more positive about the response compared to the least knowledgeable. On interpersonal trust, we similarly see large correlations across all countries such that respondents who have high trust in other people consistently report more favorably about the response. In particular, the largest correlation is observed in France (0.29), while the smallest correlation is seen in Denmark (0.10).

Altogether, the country-specific analyses corroborate the overall results and help to nuance why government vote, agreeableness, personal worry, knowledge, and interpersonal trust emerge as the most important overall predictors of support.

\section{Longitudinal individual-level variation}

An important limitation of the findings above is that they may suffer from bias. One source of bias is reversed causality (or simultaneity) such that individuals who report high levels of support are more likely to, for example, report that they are more knowledgeable in order to rationalize their support. Another source of bias is omitted variables (i.e., alternative explanations). Hence, there are a myriad of factors that potentially explains, for example, both one's reported knowledge level and one's reported support for the response. In traditional observational data, it is difficult to measure and control for all potential confounds.

We exploit the panel component in our individual-level data to increase the likelihood that our findings can be given a causal interpretation at the individual level. Specifically, we rely on the two-way fixed effects estimator described in the statistical analyses section above to increase causal leverage regarding the influence of the attitudinal correlates. ${ }^{4}$ We focus on the attitudinal correlates as these are most likely to vary within individuals over time, whereas the variation in the remaining correlates can be expected to be entirely or predominantly stable over time.

Table 2 displays the estimated effects of our attitudinal variables on support using the twoway fixed effects estimator. Column 1 shows the results from regressing support on each of the attitudinal variables, in turn, while including individual level and date fixed effects. Column 2 provides the results from including all the attitudinal variables in the same model. As is 
clear, the results are highly stable across the models, corroborating the design-based identification. These within-individual analyses support the findings above: Increases in personal worry, knowledge, and interpersonal trust foster support at the individual level, while there is no evidence of an effect of societal worry. ${ }^{5}$

Table 2: Individual-level fixed effects regression: Impacts of attitudinal variables on support

\begin{tabular}{lcc}
\hline \hline & Bivariate & Multivariate \\
\hline \multirow{3}{*}{ Covid personal worry } & $0.03^{* * *}$ & $0.03^{* * *}$ \\
& $(0.01)$ & $(0.01)$ \\
Covid societal worry & 0.01 & 0.01 \\
& $(0.01)$ & $(0.01)$ \\
Covid knowledge & $0.07^{* * *}$ & $0.07^{* * *}$ \\
& $(0.01)$ & $(0.01)$ \\
Interpersonal trust & $0.05^{* * *}$ & $0.05^{* * *}$ \\
& $(0.01)$ & $(0.01)$ \\
\hline Individual fixed effects & Yes & Yes \\
Date fixed effects & Yes & Yes \\
\hline Observations & 54,534 & 54,534 \\
Individuals & 19,370 & 19,370 \\
\hline \hline
\end{tabular}

Note: Unstandardized regression coefficients from two-way fixed effects analyses. Standard errors are two-way clustered by individual and time (in parentheses). $* * * \mathrm{p}<0.0001$. Individuals are observed between 2 and 12 times on 182 different dates.

To further probe the robustness of our results, Section C.2 in the OA displays the twoway fixed effects estimates for each country separately. Overall, Figure OA9 suggests that the estimated effects of knowledge and interpersonal trust are relatively homogeneous across countries, whereas the estimated effect of personal worry is driven by individuals in Denmark, Germany, Hungary, and the UK.

Altogether, the above results closely mirror the correlational evidence provided in the first part of the results section. The findings corroborate that knowledge and interpersonal trust are key determinants of support. Moreover, the findings identify personal worry as a potentially important driver of support in some countries.

\section{Longitudinal country-level variation}

In this final empirical section, we analyze how well our predictors explain the observed country-level differences in support. In this endeavor, we aggregate our measure of support 
as well as the predictors at the country-date level. To these data, we add information about national levels of policy stringency and national developments in the COVID-19 epidemic. The sampled countries were chosen to represent a diversity of national responses to the COVID-19 pandemic as well as a diversity in the severity of the local epidemics. Figure 4 displays these features for each country. To represent differences in government strategies, we utilize a measure of stringency of government policies over the survey period and plot it as a function of time (Hale and Webster 2020). This measure is a composite measure of the number of non-pharmaceutical interventions taken in a specific country (e.g., school closings and curfews). To represent the severity of the local epidemic, we utilize the registered daily count of new COVID-19 infections per million inhabitants. These numbers are also taken from Hale and Webster (2020). In addition, Figure 4 plots our measure of support for the government's response as a function of time.

Figure 4: Support, policy stringency, and confirmed cases
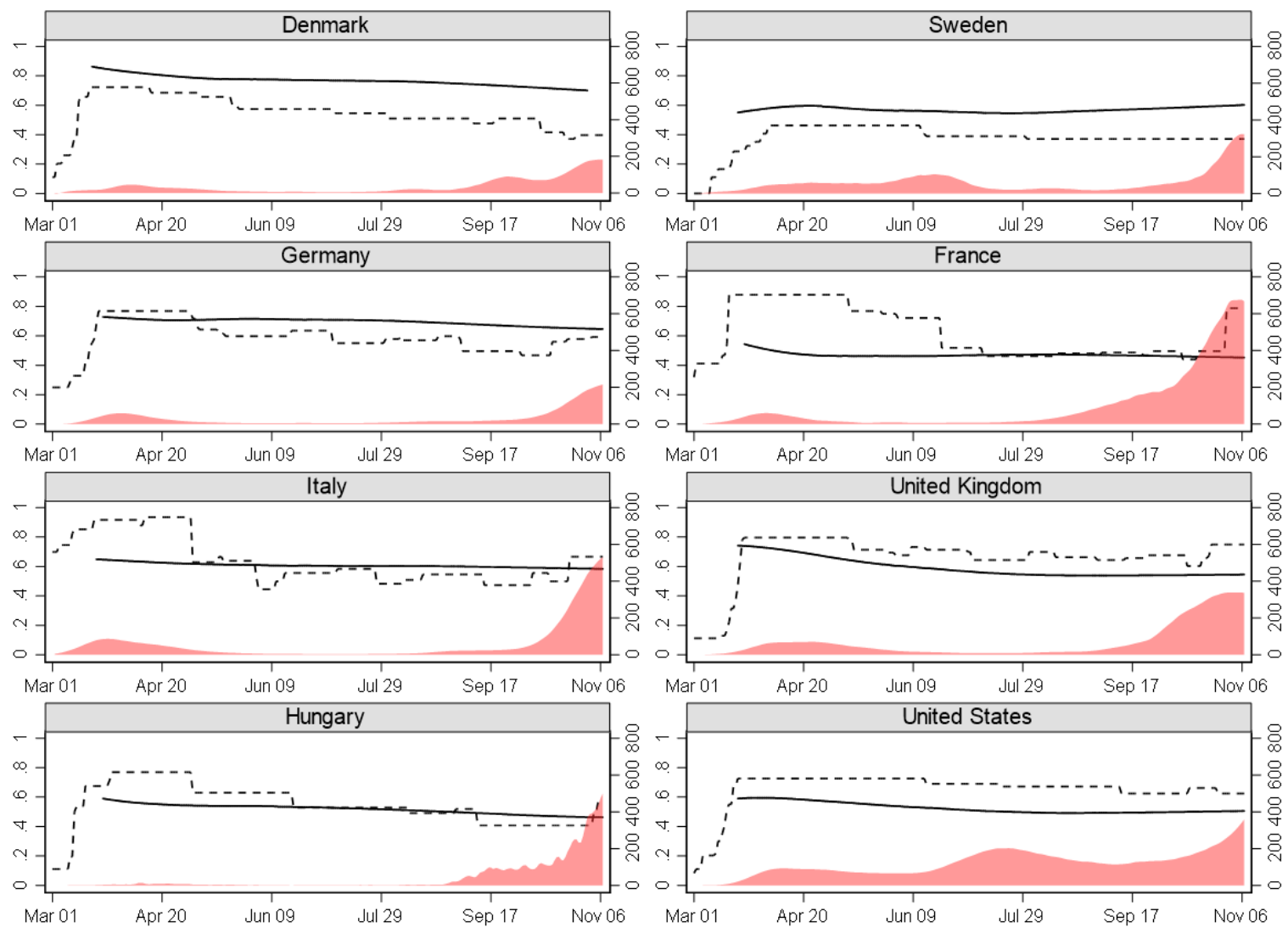

Note: Solid lines are the developments in the present measure of self-reported support using a lowess smoother. Dashed lines are the developments in policy stringency (Hale and Webster 2020). Red areas display the developments in the COVID-19 confirmed infected cases per day per million inhabitants using a kernel smoother. 
Focusing first on the pandemic development (the red curves), it is clear that all countries in our sample more or less experience parallel developments in the daily COVID-19 infection counts. Hence, we observe an initial wave in March-April, a steady development over the summer, and a second wave starting about mid-September or the beginning of October. It is important to note that although the countries follow similar developments in the epidemic, there is substantial variation in the severity level of the local epidemic across countries. Moreover, differences in the use of tests for infections means that the epidemic case counts are not directly comparable across countries. Crucially, for our purposes, however, these developments reflect what is in fact communicated to the public. Hence, it taps into the psychological processes underlying individual-level considerations whether or not to support the government's policies. ${ }^{6}$

Moving, second, to policy stringency (the dashed lines), it can be seen that all countries implemented some form of stringent measures during the first wave. However, there is also substantial variation with Sweden having the least stringent response and Italy and France the most stringent responses. Over the summer, as the development in new COVID-19 cases leveled off, most countries eased the restrictive policies. However, we also observe a substantial countrylevel variation. For example, Sweden had initially a less stringent response and did not make many adjustments over 2020. Also, United States made fewer adjustments in their response, as they did not experience the same drop in infection rates as the remaining countries in our sample did over the summer. In the remaining countries, we observe a reduction in stringency over the summer. Italy and France adjusted the most but also came from the most restrictive levels. When the second infection wave started in mid-September, we generally observe a reinstatement of more restrictive policies as a response.

Finally, focusing on the level of support for government responses (the solid line), we see moderate to high levels of support independent of the level of stringency and the severity of the pandemic, although the level of support varies substantially across countries (see also Figure 1). Furthermore, we observe a general decline in support over time in all countries with the largest decline observed in Denmark going from a high of about 90 percent approval to about 70 percent, and the smallest decline in Sweden going from about 60 percent to 50 percent. Below, we first analyze this within-country variation. Second, we focus on the variation between countries.

In Table 3, we utilize the panel structure of the aggregate country-date data with obser- 
vations for each country over time. Specifically, we apply a two-way country and time fixed effects estimator (similar to the individual-level double fixed effects estimator above) to gauge the influence of the predictors on support at the aggregate level. ${ }^{7}$ We regress support on each of the attitudinal correlates, policy stringency, the epidemic development, while including country as well as date fixed effects. Column 1 of Table 3 shows the results from bivariate regressions of support on each of the predictors, while column 2 of Table 3 displays the results from a multivariate setup. The result are more or less identical between the two models. Focusing on the multivariate model, it is clear that the country-level estimates mirror the individual-level findings: Interpersonal trust and knowledge have a clear impact on support, while the effects of the remaining variables are statistically indistinguishable from zero. A two standard deviation increase in trust increases support by about 6 percentage points $(p=0.002)$, while a two standard deviation increase in knowledge yields an increase in support by about 3 percentage points $(p=0.039)$. These are quite substantive effects. Compared to a standard deviation of about 11 percentage points on the support outcome, these effects sizes amount to about 0.55 and 0.3 of a standard deviation increase in support, respectively.

A potential methodological challenge in time-series data is the issue of autocorrelation. We tested the residuals of the multivariate model in column 2 of Table 3 , which does not indicate that autocorrelation is a significant issue. Nevertheless, in column 3 of Table 3 , we include the lagged level of support into the model. This is a way of dealing with potential issues of autocorrelation because it removes the dependence between the current level of support and its past level. Importantly, we see that the estimated effects and substantive conclusions remain fundamentally unchanged upon inclusion. ${ }^{8}$

Finally, as noted above, it appears that support for the governments response is decreasing with time. In column 4 of Table 3 , we test this formally by adding linear country-specific time trends to the multivariate model (i.e., interactions between the linear time trend and the country fixed effects). The trends pick up all time varying variation that deviates from the overall timetrend - captured in the time fixed effects - and remain unexplained by the independent variables in the model. ${ }^{9}$ The coefficient on the time trend variable gives the estimated decrease in support over a 100-days period in Denmark. In other words, this implies that over a 100-days period there is a substantial decline in support of about 7 percentage in Denmark (controlled for the 
Table 3: Country-date-level analyses from two-way fixed effects estimator models

\begin{tabular}{|c|c|c|c|c|}
\hline & Bivariate & Multivariate & Lagged DV & Time trends \\
\hline New cases $(2$ sd $)$ & $\begin{array}{l}-0.01 \\
(0.02)\end{array}$ & $\begin{array}{l}-0.01 \\
(0.02)\end{array}$ & $\begin{array}{l}0.00 \\
(0.02)\end{array}$ & $\begin{array}{l}-0.04 \\
(0.02)\end{array}$ \\
\hline Policy stringency (2 sd) & $\begin{array}{l}-0.04 \\
(0.02)\end{array}$ & $\begin{array}{l}-0.04 \\
(0.02)\end{array}$ & $\begin{array}{l}-0.03 \\
(0.02)\end{array}$ & $\begin{array}{l}-0.01 \\
(0.02)\end{array}$ \\
\hline Covid personal worry (2 sd) & $\begin{array}{l}-0.01 \\
(0.01)\end{array}$ & $\begin{array}{l}0.02 \\
(0.01)\end{array}$ & $\begin{array}{l}0.02^{*} \\
(0.01)\end{array}$ & $\begin{array}{l}0.01 \\
(0.01)\end{array}$ \\
\hline Covid societal worry (2 sd) & $\begin{array}{l}-0.02 \\
(0.02)\end{array}$ & $\begin{array}{l}-0.03 \\
(0.02)\end{array}$ & $\begin{array}{l}-0.02 \\
(0.02)\end{array}$ & $\begin{array}{l}-0.01 \\
(0.02)\end{array}$ \\
\hline Covid knowledge (2 sd) & $\begin{array}{l}0.04^{*} \\
(0.01)\end{array}$ & $\begin{array}{l}0.03^{*} \\
(0.01)\end{array}$ & $\begin{array}{l}0.03^{* *} \\
(0.01)\end{array}$ & $\begin{array}{l}0.03^{*} \\
(0.01)\end{array}$ \\
\hline Interpersonal trust (2 sd) & $\begin{array}{l}0.07^{* *} \\
(0.01)\end{array}$ & $\begin{array}{l}0.06^{* *} \\
(0.01)\end{array}$ & $\begin{array}{l}0.06^{* *} \\
(0.02)\end{array}$ & $\begin{array}{l}0.06^{* *} \\
(0.01)\end{array}$ \\
\hline Lagged support & & & $\begin{array}{l}-0.19^{*} \\
(0.07)\end{array}$ & \\
\hline Trend (100 days) (Denmark) & & & & $\begin{array}{l}-0.07^{* *} \\
(0.02)\end{array}$ \\
\hline$\times$ France & & & & $\begin{array}{l}0.05^{*} \\
(0.02)\end{array}$ \\
\hline$\times$ Germany & & & & $\begin{array}{l}0.00 \\
(0.00)\end{array}$ \\
\hline$\times$ Hungary & & & & $\begin{array}{l}-0.01 \\
(0.01)\end{array}$ \\
\hline$\times$ Italy & & & & $\begin{array}{l}0.01 \\
(0.01)\end{array}$ \\
\hline$\times$ Sweden & & & & $\begin{array}{l}0.01 \\
(0.02)\end{array}$ \\
\hline$\times$ United Kingdom & & & & $\begin{array}{l}-0.05^{* * *} \\
(0.004)\end{array}$ \\
\hline$\times$ United States & & & & $\begin{array}{l}-0.02^{* *} \\
(0.01)\end{array}$ \\
\hline Country fixed effects & Yes & Yes & Yes & Yes \\
\hline Date fixed effects & Yes & Yes & Yes & Yes \\
\hline Observations & 1,203 & 1,203 & 1,107 & 1,203 \\
\hline
\end{tabular}

Note: Unstandardized regression coefficients from two-way fixed effects analyses. Standard errors are clustered by country (in parentheses). ${ }^{*} \mathrm{p}<0.05,{ }^{* *} \mathrm{p}<0.01,{ }^{* *} \mathrm{p}<0.001$. N $($ countries $)=8 ; \mathrm{N}$ (time-periods $)=135$ (France) -166 (Denmark).

other factors in the model). The coefficients for the remaining countries give the estimated deviations in these countries compared to the Danish trend. Hence, the German, Hungarian, Italian, and Swedish trends are not statistically significantly different from the Danish trend. To the contrary, we see that the French trend is significantly less negative compared to the 
Danish, while the British and American trends are significantly more negative. Overall, the trends substantively show that the farther away we get from the initial outbreak of the virus, the less mobilized citizens are. Put differently, the trends illustrate an increase in fatigue over time and that collective mobilization is not indefinite.

The findings above suggest that aggregate changes in (1) the degree to which citizens' feel they know enough about what to do in relation to the coronavirus, (2) aggregate changes in interpersonal trust, and (3) to some extent aggregate changes in personal worry play a key role in explaining differences in the country-specific developments in support, observed in Figure 4.

In Figure OA11 in the OA, we move from the focus of explaining differences in developments of support to explaining differences in the levels of support between countries. It is important to note that these analyses are highly limited in terms of statistical power by the fact that they only include eight national cases. As an example, it makes little sense to move beyond the simple bivariate correlations displayed in Figure OA11 because of a high risk of overfitting the data. This limits our ability to control for other factors when conducting the analyses. With such limitations in mind, the analyses are nonetheless informative. Hence, the analyses support the conclusions above that knowledge and interpersonal trust seems to be the most powerful predictors in explaining variations in support (please see Section D.2 for details). Interestingly, personal and societal worry correlate negatively with support at the aggregate level. There is less support for the government's response in the countries where people are most concerned about COVID-19. This could reflect that concern increases and support decreases in countries where responses have been less effective. Overall, however, these between-country findings underscore the importance of mobilizing prosocial motivations to generate support for the government's responses during a crisis such as COVID-19.

\section{Discussion}

In this article, we asked two questions: First, did citizens generally support or oppose the policy response of their government against the COVID-19 pandemic during 2020? And, second, which factors explain variation in support of their government's response across individuals, time and countries? To answer these questions, we relied on large-scale, online surveys reflective of the populations of eight Western democracies: Denmark, France, Germany, Hungary, Italy, 
United Kingdom, United States and Sweden. We started collecting data 10-14 days after Italy as the first Western country closed down and rely on data collected until November 2020.

The results showed that support for the imposed policy responses varied from being about neutral to being relatively high across the countries under analysis. Accordingly, the findings document that it is possible to generate widespread public support even for unprecedented and highly invasive policies. At the same time, it is relevant to note that there is some indication of opposition in specific countries.

The analyses of the factors shaping variation in support for the government's response to COVID-19 showed little effect of traditionally relevant demographic and political cleavages. Despite the fact that factors such as age and socioeconomic status shape the costs and benefits associated with stringent policies, we found no evidence that these demographic factors influenced support. The one exception is the perhaps most obvious political correlate to predict support: Vote choice. Our results demonstrate substantial partisan bias such that government voters are much more supportive of the government's response against COVID-19 across all countries. In contrast, ideology and populist support for strong leaders did not relate to overall support for the government's COVID-19-response across the countries.

Beyond vote choice, we found strong evidence that support was driven by two factors related to prosocial motivations: Interpersonal trust and agreeableness. Interpersonal trust stands out as the most important predictor of response support but also the personality trait of agreeableness is consistently related to support across statistical models. In addition, we found selfassessed knowledge to be crucial for predicting support: Respondents who feel highly knowledgeable about COVID-19 are substantially more positive about the government response compared to respondents who do not feel knowledgeable. Additional analyses confirmed the crucial importance of interpersonal trust and knowledge. Thus, changes in trust and knowledge causally influence changes in support over time at both the individual- and country-level. Furthermore, between-country differences in levels of trust and knowledge were positively associated with between-country differences in support.

In contrast to these factors related to prosociality, we found little effect of fear-related factors. Personal worry about the effects of COVID-19 significantly predicted support for the government's response in most specifications but the effects were generally smaller than the 
effects of trust and knowledge. Also, we found no effect of the personality trait of neuroticism. Furthermore, we found little effect of a measure of sociotropic COVID-19-related fears: societal worry (i.e., the extent to which someone is concerned about the negative effects of the pandemic on their communities). In the benchmark models in the Results section, we find no evidence that such worries predict support. There are several potential explanations for the limited nature of the relationship between fear (whether personal or societal in nature) and support for the government responses. One possibility is that these worries also reflect concerns about the adverse impact of stringent responses (e.g., in the financial domain), which would make people less likely to support the stringent responses of governments. Another possibility is that people who are highly concerned would like governments to respond with even more stringency. It is important to note that this article simply assesses support for the set of policies that each specific government defined as the appropriate and necessary response. Some citizens may have wanted the government to go further. A final and complimentary possibility is that prosocial motivations can be elicited independently of a person's own worries. Potentially, those who are trusting and agreeable take note of others' fears and act accordingly.

Overall, our findings suggest that the highly invasive policies designed to stop the spread of COVID-19 in 2020 tapped into motivations related to collective action. Accordingly, in building support for their policies from beyond their regular voter base, governments' success critically hinged on their ability to clearly formulate a collective project where people, first, knew individually what to do for protection and, second, trusted that others were doing the same. According to the analyses at the country level, this mobilization of people in support of the collective project of halting COVID-19 was possible independently of the severity of the epidemic and the stringency of the response, which suggested that support could be generated even for swift and strong interventions preceding accelerated growth in infections in March 2020. At the same time, our findings also indicate that this mobilization did not last forever. Consistent with general findings on the emergence and unravelling of collective action (Fehr and Gachter 2000), support slowly diminished over the year of 2020; presumably as an effect of both fatigue (Lilleholt et al. 2020) and of discussions about proper responses as well as observations of free-riding on the recommendation of the health authorities. On this basis, the best prediction is that the governments of Western democracies may face increasing polarization and opposition 
over their handling of COVID-19 as the pandemic continues.

\section{Acknowledgements}

This study has been funded by grant CF20-0044 from the Carlsberg Foundation to Michael Bang Petersen. FJ, AB and MBP designed the study; FJ, AB, MFL and MBP collected the data; FJ analyzed the data; FJ, $\mathrm{AB}$ and MBP drafted and revised the paper. All data and required code is publicly available in a repository at the webpage of the Open Science Framework: https://osf.io/vuaw5/. We are grateful for research assistance from Magnus Storm Rasmussen.

\section{Notes}

${ }^{1}$ Utilizing a rolling panel sample design, the survey firm Epinion sample adult respondents using online panels. Panelists are compensated via lotteries for gift certificates. In our study, the median interview length, across all countries, was 9 minutes. Among the panelists invited to take our survey, the response rate (calculated as the fraction of complete responses over invited, eligible participants) was between 18\% (Hungary) and $38 \%$ (Denmark). The survey was conducted in line with the national ethical guidelines for conducting survey-based research involving human subjects. Informed consent was obtained from each participant at the beginning of the survey.

${ }^{2}$ We run a number of robustness checks, as described here and below. We first rerun the models described above while also allowing the slopes of the predictors to vary over time (i.e., by data wave). This allow us to investigate whether the strength of the associations between support and the psychological predictors changes in time. Except for societal worry, we find no consistent time trends in the strength of the associations (see Section B.1 in the OA for details). Therefore, we focus on the models that pool observations over time in the main text. We discuss the association between support and societal worry in detail below. Second, we re-estimate the fourth (attitudinal) model while including (a) left-right self-placement as a covariate and (b) the personality trait variables as covariates. Overall, the results replicate those presented in the main text (see Section B.2 in the OA). Third, we also replicate our results while employing post-stratification weights. Weights have been calculated by the data provider, and include data on party choice, region, education, age and gender interactions, house type and household size. These weights ensure that our samples are informative of the population in these respect. Importantly, the weighted results remain fundamentally unchanged as compared to the unweighted results presented in the main text (see Section B.3 in the OA for details). Fourth, and finally, we rerun the main analyses, while shifting our outcome from support for the government response to an alternative outcome that asks respondents about their confidence in the government (see section B.4 of the OA). All results replicate those presented in the main text. 
${ }^{3}$ In public opinion models, knowledge is commonly included as moderator of the effects of other variables (Zaller et al. 1992). In Figure OA6, we therefore model potential interactions between knowledge and the remaining attitudinal correlates. Overall, these analyses show that the correlation between support and knowledge is strikingly homogeneous over the range of both interpersonal trust and societal worry, while the correlation varies somewhat across the range of personal worry. Specifically, we observe a statistically significant interaction between knowledge and personal worry of about 6.5 percentage points $(p<0.0001)$, indicating that the correlation between support and knowledge is about 6.5 percentage points stronger among individuals high on worry compared to individuals who are unworried. Specifically, among the unworried the marginal correlation between support and knowledge is 0.14 , while the it is 0.205 for the most worried (please see details in section B.5 of the OA). Knowing what to do generates stronger support for the government's efforts among those who also fear COVID-19.

${ }^{4}$ The estimator gives an unbiased estimate of the causal influence of the attitudinal variables on support on the assumption that the response support of individuals had followed parallel trends in the absence of changes in these variables. In other words: Absent a change in attitudes, all individuals would have experienced similar developments in support. This assumption can be violated in two ways described above: Reversed causality and omitted variable bias. With many waves of data, we are able to indirectly assess the plausibility of the parallel trends assumption. Section C.1 in the OA offers evidence for the plausibility of this assumption.

${ }^{5}$ Note that the estimated effects correspond to moving from the minimum to maximum on each of the correlates. Evaluated against a 2 standard deviation increase, personal worry increase support by about 1.7 percentage points, knowledge increase support by about 3 percentage points, while interpersonal trust increase support by about 2.8 percentage points. While these effect sizes are small in an absolute sense, the estimated effects are nonetheless relatively large compared to an overall standard deviation of 32 percentage points on the support measure. This, for example, means that a two standard deviation increase in knowledge moves support by 0.1 of a standard deviation.

${ }^{6}$ In addition, we repeated the models reported in 3 replacing daily COVID-19 infection counts with daily number of COVID-19-related deaths. This latter metric may be more comparable across time and countries. This replacement does not change any of the reported conclusions.

${ }^{7}$ As with the individual-level fixed effects estimators, the causal interpretation of our estimates rely on the parallel trends assumption. In Figure OA10 in the OA, we test the plausibility of the parallel trends assumption by including leads on the effects. Crucially, the estimated coefficients on the leads are close to 0 and far from conventional levels of statistical significance. Moreover, the estimated impacts of the immediate effects remain fundamentally unchanged upon control for the leads. In other words, we do not observe an increase in support that precedes changes in the predictors. This corroborate the design-based identification strategy and, hence, the causal interpretation of the estimated effects.

${ }^{8}$ As an additional robustness check, we also included a first-order autoregressive (AR1) structure into the model. This did not change the reported conclusions. Substantially, it should also be noted that the inclusion of a lagged dependent variable is commonly used to assess the potential long-term effects of the independent variables. Specifically, long-term effects are calculated by dividing the coefficient of each independent variable by 1 minus the coefficient of the lagged dependent variable. Interpersonal trust and knowledge gives long-term 
effects of about 4 and 7 percentage points, respectively, which are similar to the coefficients in the multivariate and bivariate models. This indicates that the predictors have no additional impact on support beyond their immediate effects. In Figure OA10 we included lags on the effects of each predictor. These lags similarly capture long-term impacts on support. The conclusions from these models are similar: There is very little evidence that the predictors impact on support beyond their immediate effects.

${ }^{9}$ Note that including such unit-specific time trends is another common way of gauging the plausibility of the parallel trends assumption: If the estimated effects remain similar after inclusion of the unit-specific trends, it corroborates the assumption. The fourth column of Table 3 shows that it makes no difference whether we include the unit-specific trends or not and, hence, this provides further support for the the robustness of our results.

\section{References}

Angrist, Joshua D. and Jörn-Steffen Pischke. 2008. Mostly Harmless Econometrics: An Empiricist's Companion. Princeton University Press.

Beall, Alec T, Marlise K Hofer and Mark Schaller. 2016. "Infections and elections: Did an Ebola outbreak influence the 2014 US federal elections (and if so, how)?" Psychological Science 27(5):595-605.

Blundell, Richard, Monica Costa Dias, Robert Joyce and Xiaowei Xu. 2020. "Covid-19 and inequalities." Fiscal Studies .

Bol, Damien, Marco Giani, André Blais and Peter John Loewen. 2020. "The effect of COVID19 lockdowns on political support: Some good news for democracy?" European Journal of Political Research pp. 1-9.

Bolsen, Toby, James N Druckman and Fay Lomax Cook. 2014. "The influence of partisan motivated reasoning on public opinion." Political Behavior 36(2):235-262.

Clemmensen, Christoffer, Michael Bang Petersen and Thorkild IA Sørensen. 2020. "Will the COVID-19 pandemic worsen the obesity epidemic?" Nature Reviews Endocrinology pp. 1-2.

Fehr, Ernst and Simon Gachter. 2000. "Cooperation and punishment in public goods experiments." American Economic Review 90(4):980-994.

Gerber, Alan S., Gregory A. Huber, David Doherty and Conor M. Dowling. 2011. "The Big Five 
Personality Traits in the Political Arena." Annual Review of Political Science 14(1):265-287.

URL: https://doi.org/10.1146/annurev-polisci-051010-111659

Goodell, John W. 2020. "COVID-19 and finance: Agendas for future research." Finance Research Letters p. 101512.

Hahn, Elisabeth, Juliana Gottschling and Frank M Spinath. 2012. "Short measurements of personality-Validity and reliability of the GSOEP Big Five Inventory (BFI-S)." Journal of Research in Personality 46(3):355-359.

Hale, Thomas and Samuel Webster. 2020. "Oxford COVID-19 government response tracker.".

Jensen, Carsten and Michael Bang Petersen. 2017. "The deservingness heuristic and the politics of health care." American Journal of Political Science 61(1):68-83.

Johnson, Tim, Christopher Dawes, James Fowler and Oleg Smirnov. 2020. "Slowing COVID19 transmission as a social dilemma: Lessons for government officials from interdisciplinary research on cooperation." Journal of Behavioral Public Administration 3(1).

Jørgensen, Frederik, Alexander Bor and Michael Bang Petersen. 2020. "Compliance Without Fear : Predictors of Protective Behavior During the First Wave of the COVID-19 Pandemic." PsyArXiv Working Paper .

URL: https://doi.org/10.31234/osf.io/uzwgf

Kam, Cindy D and Beth A Estes. 2016. "Disgust sensitivity and public demand for protection." The Journal of Politics 78(2):481-496.

Lewnard, Joseph A and Nathan C Lo. 2020. "Scientific and ethical basis for social-distancing interventions against COVID-19." The Lancet. Infectious diseases 20(6):631.

Lilleholt, Lau, Ingo Zettler, Cornelia Betsch and Robert Böhm. 2020. "Correlates and Outcomes of Pandemic Fatigue.".

Maddux, James E and Ronald W Rogers. 1983. "Protection motivation and self-efficacy: A revised theory of fear appeals and attitude change." Journal of experimental social psychology 19(5):469-479. 
Mede, Niels G and Mike S Schäfer. 2020. "Science-related populism: Conceptualizing populist demands toward science." Public Understanding of Science 29(5):473-491.

Mondak, Jeffery J. 2010. Personality and the foundations of political behavior. Cambridge University Press.

Mudde, Cas and Cristóbal R Kaltwasser. 2014. "Populism and political leadership." The Oxford handbook of political leadership pp. 376-388.

Ostrom, Elinor. 1998. "A behavioral approach to the rational choice theory of collective action: Presidential address, American Political Science Association, 1997." American Political Science Review 92(1):1-22.

Paek, Hye Jin, Karen Hilyard, Vicki S. Freimuth, J. Kevin Barge and Michele Mindlin. 2008. "Public support for government actions during a flu pandemic: lessons learned from a statewide survey." Health promotion practice 9(4 Suppl):60-72.

Pfattheicher, Stefan, Laila Nockur, Robert Böhm, Claudia Sassenrath and Michael Bang Petersen. 2020. "The emotional path to action: Empathy promotes physical distancing during the COVID-19 pandemic.".

Promislow, Daniel EL. 2020. "A geroscience perspective on COVID-19 mortality." The Journals of Gerontology: Series A.

Rieger, M. O. and M. Wang. 2020. "Trust in Government Actions during the COVID-19 Crisis." pp. 1-23.

Rippetoe, Patricia A and Ronald W Rogers. 1987. "Effects of components of protectionmotivation theory on adaptive and maladaptive coping with a health threat." Journal of Personality and Social Psychology 52(3):596.

Steinkopf, Leander. 2017. "Disgust, empathy, and care of the sick: an evolutionary perspective." Evolutionary Psychological Science 3(2):149-158.

Tetlock, Philip E. 1986. "A value pluralism model of ideological reasoning." Journal of personality and social psychology 50(4):819. 
Timotijevic, Jelena. 2020. "Society's 'New Normal'? The Role of Discourse in Surveillance and Silencing of Dissent During and Post Covid-19.".

Tyler, Tom R. 2006. Why people obey the law. Princeton University Press.

Van Bavel, Jay J, Aleksandra Cichocka, Valerio Capraro, Hallgeir Sjåstad, John B Nezlek, Mark Alfano, Flavio Azevedo, Aleksandra Cislak, Patricia Lockwood, Robert M Ross and et al. 2020. "National identity predicts public health support during a global pandemic: Results from 67 nations.".

URL: psyarxiv.com/ydt95

Wikipedia. 2020. "Protests over responses to the COVID-19 pandemic.".

URL: https://en.wikipedia.org/wiki/Protests ver $_{r}$ esponses $t_{t} o_{t}$ he $_{C} O V I D-19_{p}$ andemic

Zaller, John R et al. 1992. The nature and origins of mass opinion. Cambridge university press.

\section{Disclosure statement}

No potential conflict of interest was reported by the authors.

\section{Notes on contributors}

Frederik Jørgensen is a Postdoctoral Researcher at Department of Political Science at Aarhus University. ORCID: 0000-0002-5461-912X [fj@ps.au.dk]

Alexander Bor is a Postdoctoral Researcher at Department of Political Science at Aarhus University. ORCID: 0000-0002-2624-9221 [alexander.bor@ps.au.dk]

Marie Fly Lindholt is a Scientific Assistant at Department of Political Science at Aarhus University. ORCID: 0000-0002-8044-2559 [mfl@ps.au.dk]

Michael Bang Petersen is a Professor at Department of Political Science at Aarhus University. ORCID: 0000-0002-6782-5635 [michael@ps.au.dk] 


\section{Online Appendix}

\section{Contents}

\begin{tabular}{|l}
\hline A Materials and Methods \\
\hline
\end{tabular}

A.1 Data collection . . . . . . . . . . . . . . . . . . . . . 2

A.2 Personality trait statements . . . . . . . . . . . . . . . . . . 3

A.3 Bivariate correlations . . . . . . . . . . . . . . . . . . . . . 4

B Supporting Results: Multilevel models

B.1 Temporal dynamics . . . . . . . . . . . . . . . . . . . . . . . . . 6

B.2 Full models . . . . . . . . . . . . . . . . . . . . . . . . . 7

B.3 Post-stratification weights $\ldots \ldots \ldots \ldots \ldots \ldots$

B.4 Alternative outcome . . . . . . . . . . . . . . . . . . . . . . 9

B.5 Interactions between Covid knowledge and each of the remaining attitudinal correlates . . . . . . . . . . . . . . . . . . . . . . . . . 10

B.6 The correlation between support and societal worry, temporal dynamic . . . . . . 11

\begin{tabular}{ll|}
\hline C Supporting Results: Individual-level longitudinal variation & 12
\end{tabular}

C.1 Estimating the individual-level fixed effects, leads . . . . . . . . . . . . . . . 12

C.2 Estimating the individual-level fixed effects, by country . . . . . . . . . . . . 13

\begin{tabular}{|l|l|l|l|l}
\hline S Supporting Results: Country-level analyses & 14
\end{tabular}

D.1 Estimating the country-level fixed effects, leads and lags . . . . . . . . . . . . . 14

D.2 Explaining aggregate differences in levels of support across countries . . . . . . . 15 


\section{A Materials and Methods}

\section{A.1 Data collection}

Table OA1: Overview of data collection

\begin{tabular}{llr}
\hline Country & Dates & Observations \\
\hline Denmark & March 19 - October 31 & 24,358 \\
Sweden & March 21 - November 7 & 14,339 \\
Germany & March 24 - November 7 & 13,934 \\
France & March 24 - November 7 & 13,846 \\
Italy & March 21 - November 7 & 14,798 \\
Hungary & March 24 - November 7 & 13,904 \\
United Kingdom & March 21 - November 7 & 14,424 \\
United States & March 21 - November 7 & 14,459 \\
\hline
\end{tabular}




\section{A.2 Personality trait statements}

On neuroticism, we provided the following three statements: (1) ... is often concerned, (2) ... easily gets nervous, and (3) is good at staying cool in stressful situations. Together, the three items form a reliable scale, $\alpha=0.69$. On extraversion, respondents got the following statements: (1) ... likes to chat, (2) . . is extrovert and sociable, and (3) is good at staying cool in stressful situations $(\alpha=0.77)$. On openness, we gave the following statements: $(1) \ldots$ gets lots of new ideas, (2) ... appreciates art and aesthetics, and (3) has a vivid imagination and can think of things that do not yet exist $(\alpha=0.65)$. On agreeableness, respondents considered the following statements: (1) ... is sometimes impolite to, (2) . . is forgiving towards other, and (3) is kind and considerate towards almost everyone $(\alpha=0.49)$. On conscientiousness, we provided respondents with the following statements: (1) ... is thorough and meticulous, (2) $\ldots$ is rather lazy, and (3) is effective when I do something $(\alpha=0.44)$. 


\section{A.3 Bivariate correlations}

Figure OA1: Bivariate correlations
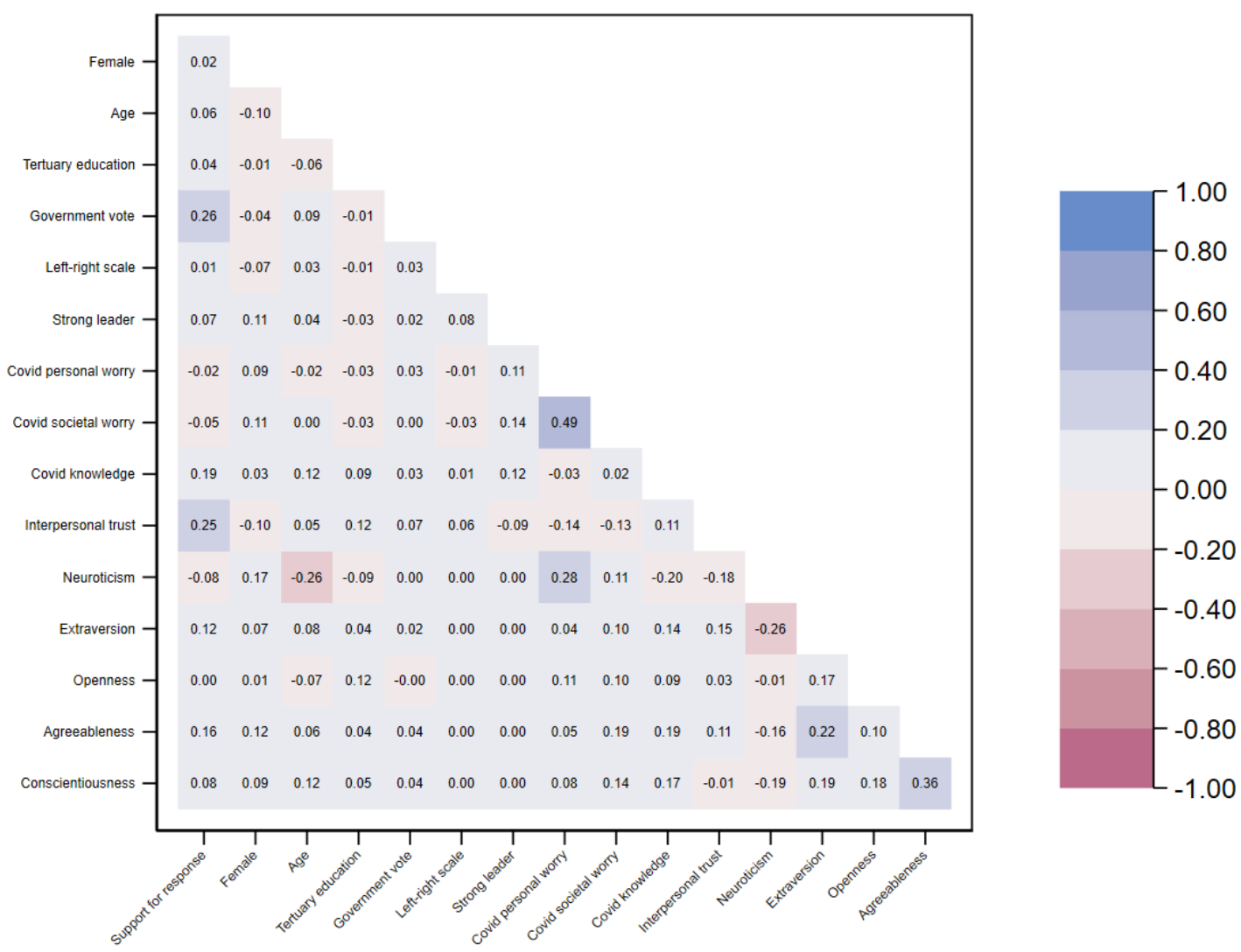


\section{B Supporting Results: Multilevel models}

In the supporting results section of the OA, we present results from analyses that (1) extends the sample (see Section B.1), (2) re-estimate the attitudinal correlates model in Figure OA3 while including (a) all political variables and (b) the personality trait variables as covariates, (3) apply post-stratification weights, (4) uses confidence in the government as an alternative outcome (see Section B.4), and (5) shows the correlation between support and societal worry when dropping personal worry from the statistical model (see Section B.6). 


\section{B.1 Temporal dynamics}

In this section, we replicate the results of model 4 in Figure 2 (the attitudinal correlates model) of the main text while also allowing the slopes to vary over survey rounds. Results below show that there are no consistent trends in the correlations over time. This is the reason why we rely on the country random slope model in the main text. Note that we discuss how societal worry varies over time in more detail in the main text.

Figure OA2: Temporal dynamics
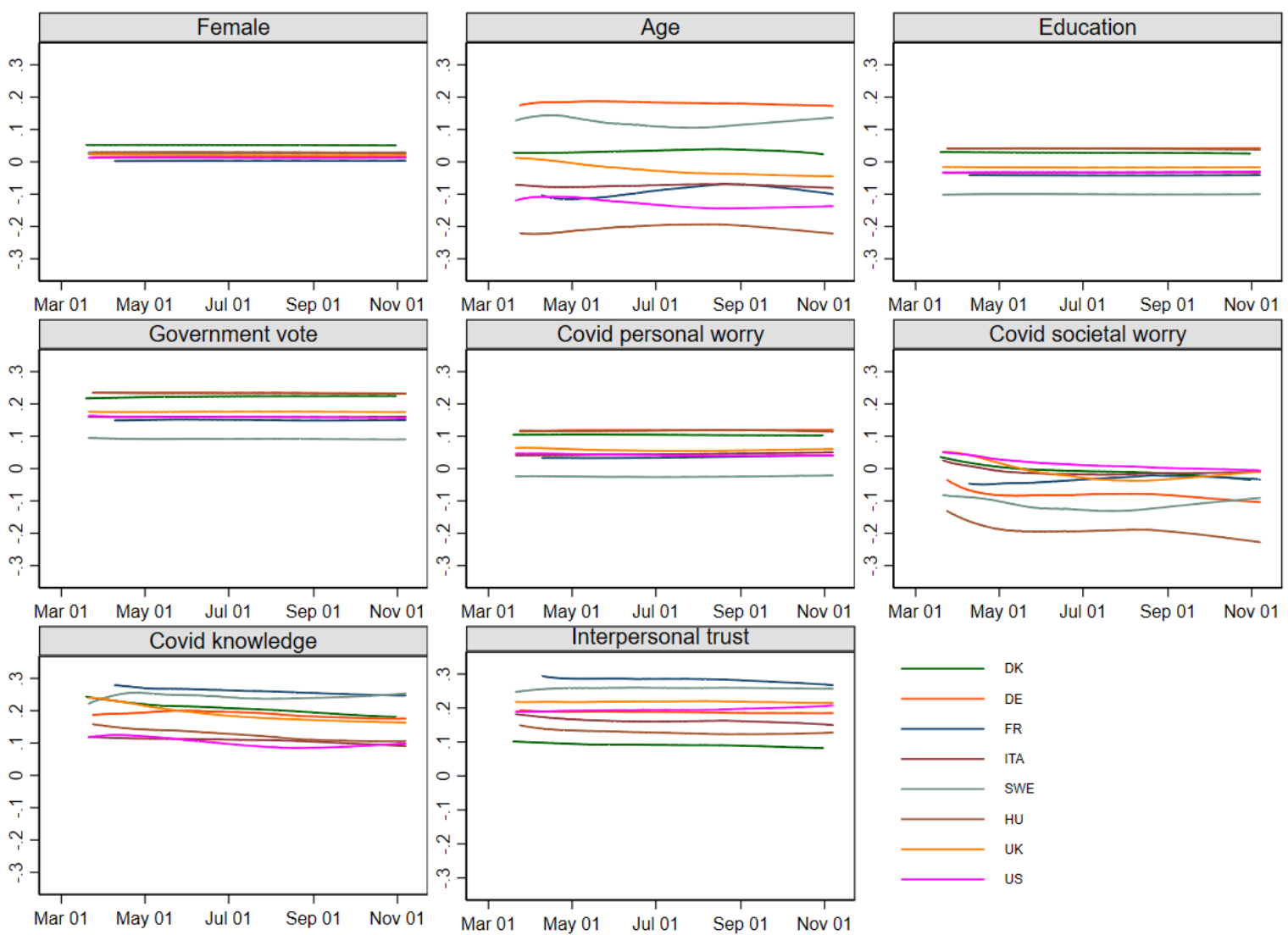

Note: Estimated correlations that allow the associations to vary in time. The outcome is scaled $0-1$ such that coefficients correspond to percentage point changes. 


\section{B.2 Full models}

In this section, we we re-estimate the fourth model (the attitudinal correlates model) in Figure OA3 while including (a) all political variables and (b) the personality trait variables as covariates. Overall, results replicate those presented in the main text.

Figure OA3: Correlations, full models

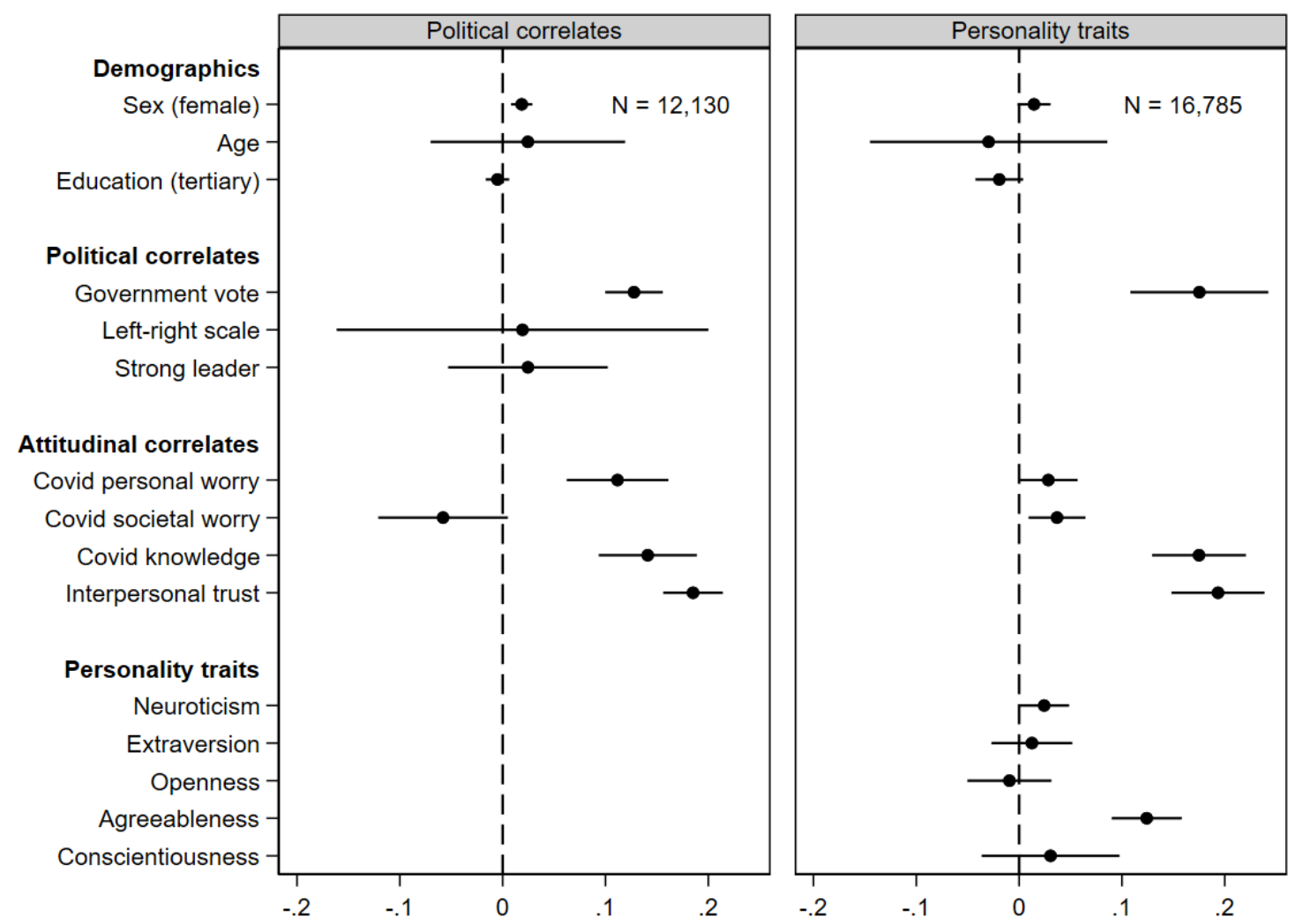

Note: Estimated correlations from our attitudinal model that add political correlates and personality traits. The outcome is scaled 0-1 such that coefficients correspond to percentage point changes. 


\section{B.3 Post-stratification weights}

In this section, we replicate our results while employing post-stratification weights. These weights have been calculated by the data provider, and include data on party choice, region, education, age and gender interactions, house type and household size. The weights ensure that our samples are informative of the population in these respect. Importantly, the weighted results remain fundamentally unchanged as compared to the unweighted.

Figure OA4: Correlations, post-stratification weights
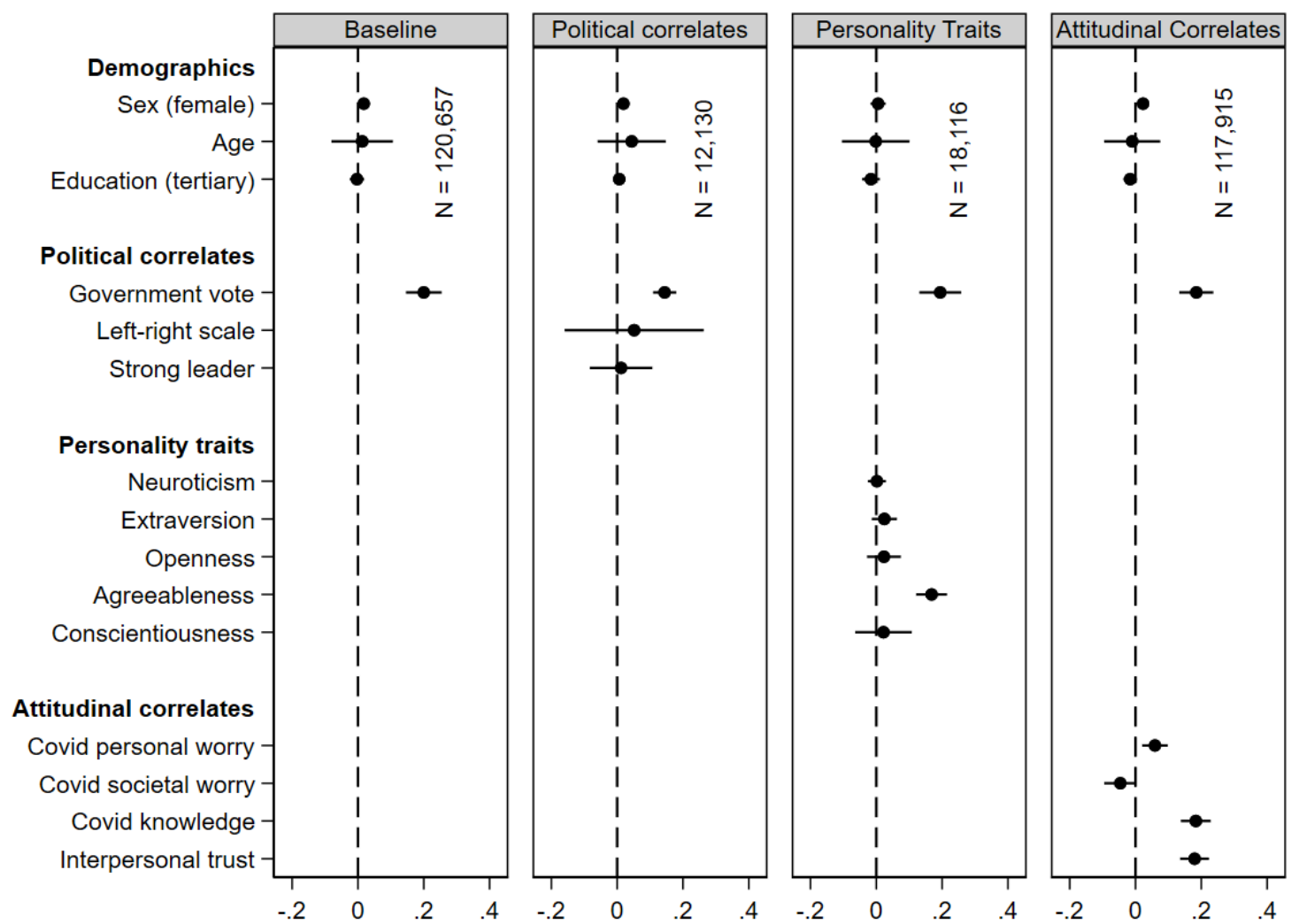

Note: Estimated correlations from our benchmark model. First panel: Baseline. Second panel: Adds Left-right self-placement and preference for a strong leader. Third panel: Adds personality traits (observed only until March 31). Right panel: Adds attitudinal correlates (for Fance we only have observations from April 9 and onwards). Filled black circles are the estimated correlations. Horizontal bars are the associated $95 \%$ confidence intervals. The outcome is scaled 0-1 such that coefficients correspond to percentage point changes. 


\section{B.4 Alternative outcome}

In Figure OA5, we replicate the results of Figure 2, while shifting the outcome from support of the government response to trusting the government. Specifically, we utilize a standard question that asks: "On a scale from 0 to 10, how much confidence do you personally have in the government?" All results of the main text is robust to shifting the outcome.

Figure OA5: Correlations, confidence in government

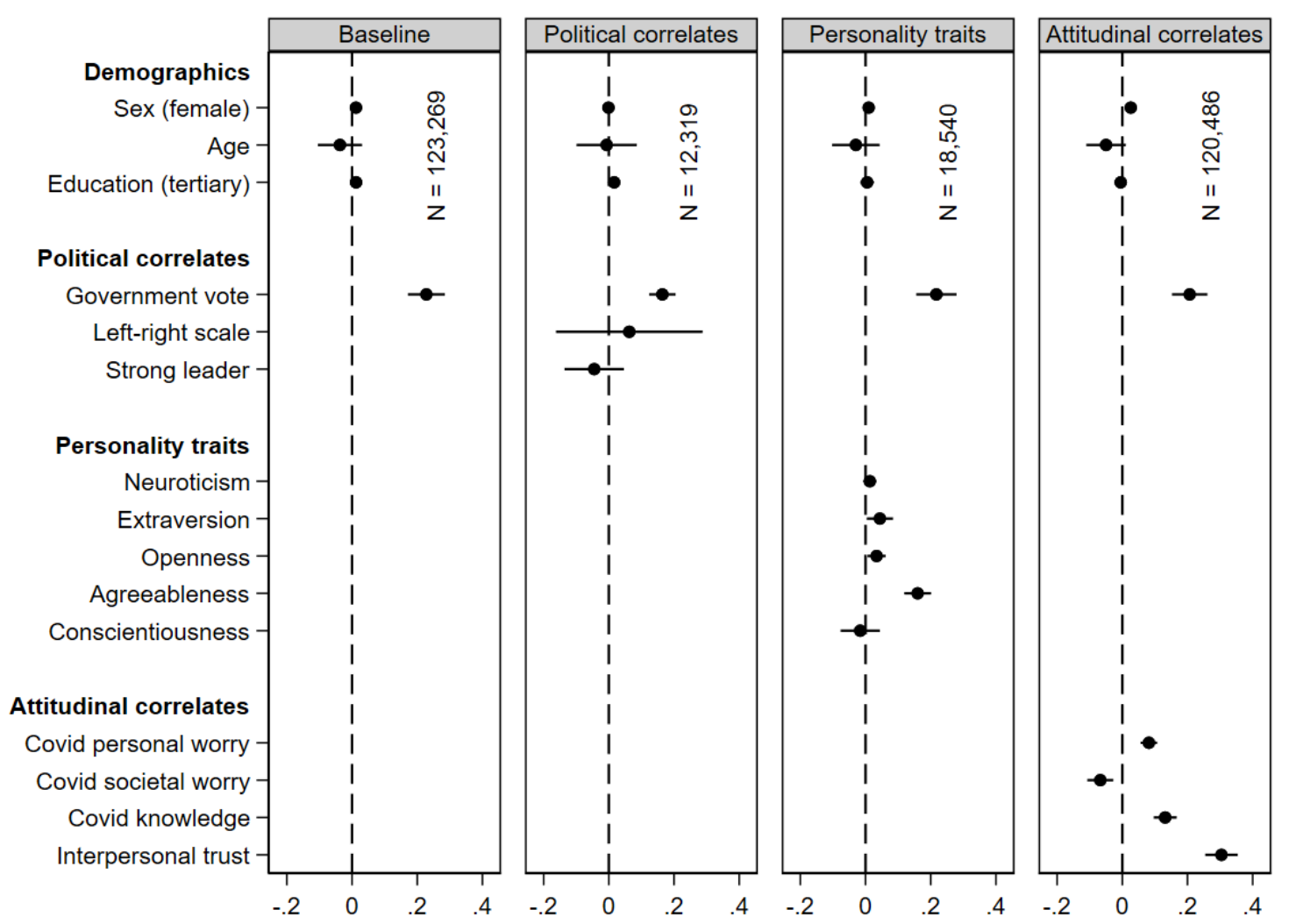

Note: Estimated correlations from our benchmark models. Filled black circles are the estimated correlations. Horizontal bars are the associated $95 \%$ confidence intervals. The outcome is scaled $0-1$ such that coefficients correspond to percentage point changes. 


\section{B.5 Interactions between Covid knowledge and each of the remaining atti- tudinal correlates}

In Figure OA6 below, we interact covid knowledge with each of the three remaining attitudinal correlates (personal worry, societal worry, and interpersonal trust) and include the interaction into the attitudinal correlates model from Figure 2 of the main text. The results below show that while the knowledge correlation is strikingly stable across both societal worry and interpersonal trust, there is a degree of heterogeneity over personal worry. In particular, we observe a statistically significant interaction term between knowledge and personal worry of about 6.5 percentage points $(p<0.0001)$. In other words, the correlation between support and knowledge is about 6.5 percentage points stronger among individuals high on worry compared to individuals who are unworried. Specifically, we observe a correlation between support and knowledge of about .14 among those who are not worried, while the correlation is about .205 for those who are most worried.

Figure OA6: Correlation between support and societal worry when dropping personal worry

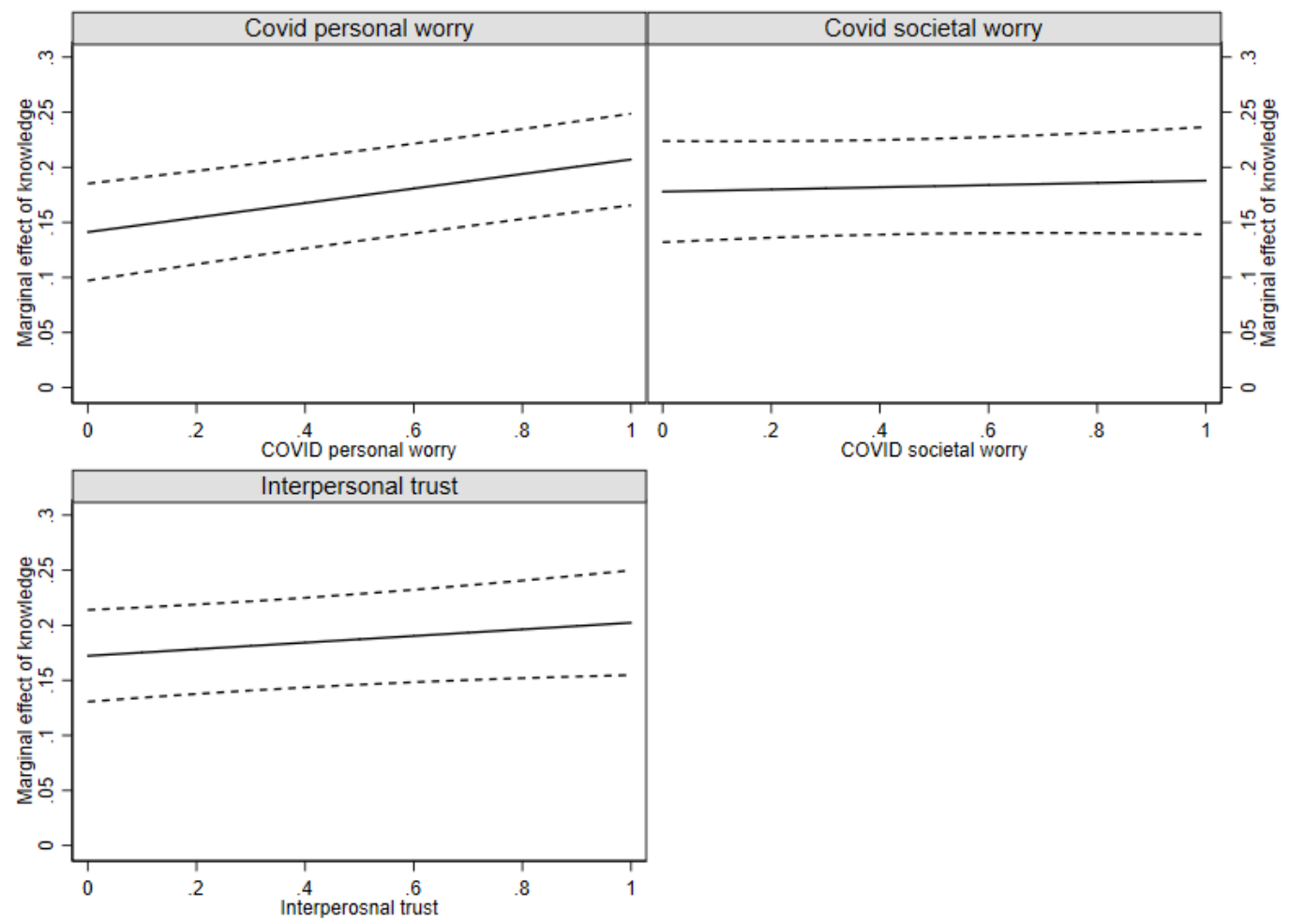

Note: Solid black lines show the marginal correlations between knowledge and support across the range of each of the moderators. Dashed lines are the associated $95 \%$ confidence intervals. The outcome is scaled $0-1$ such that coefficients correspond to percentage point changes. 


\section{B.6 The correlation between support and societal worry, temporal dynamic}

In Figure OA7, we estimate the correlation between support and societal worry, while allowing the association to vary in time. Note we exclude the other attitudinal correlates in this model. Overall, we observe a relatively strong positive correlation in Denmark, the US, the UK, Italy, and Germany in the initial lock-down phase of the pandemic. In these countries, we see that the correlation drops toward 0 as the policy restrictions are lifted and societies re-open. To the contrary, we observe a moderately negative association throughout the period in France and strong negative correlations in Sweden and Hungary.

Figure OA7: Correlation between support and societal worry when dropping personal worry

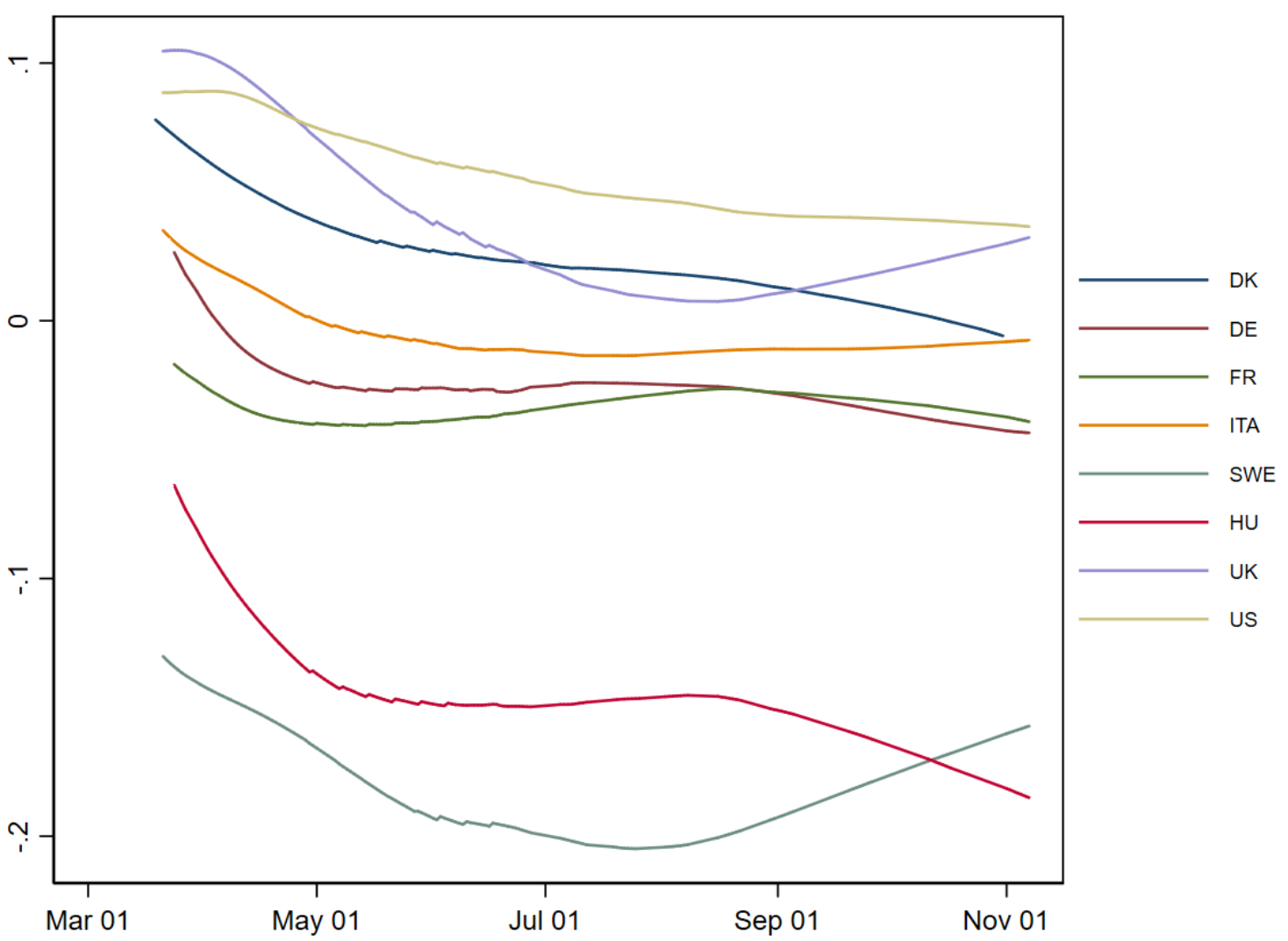

Note: Estimated correlations from our benchmark model. Filled black circles are the estimated correlations. Horizontal bars are the associated $95 \%$ confidence intervals. Hollow circles are reference categories. The outcome is scaled $0-1$ such that coefficients correspond to percentage point changes. 


\section{Supporting Results: Individual-level longitudinal variation}

\section{C.1 Estimating the individual-level fixed effects, leads}

Figure OA8 tests the robustness of this parallel trends assumption. We run models with one and two leads, respectively, on the effects of each the attitudinal variables. The blue filled circles provide the estimates from a model with two leads, while the red filled triangles provide the estimates from a model with one lead. Crucially for the plausibility of the parallel trends assumption, the estimated coefficients on the leads are generally close to 0 and far from conventional levels of statistical significance. Moreover, we observe that the estimated impacts of the immediate effects remain fundamentally unchanged, when including the leads. Taken together, these findings provide evidence that individuals did not begin increasing their level of support prior to a change in the attitudinal variables and hence corroborate the parallel trends assumption that underpins the causal interpretation of the estimated effects.

Figure OA8: Individual-level fixed effects, lead model

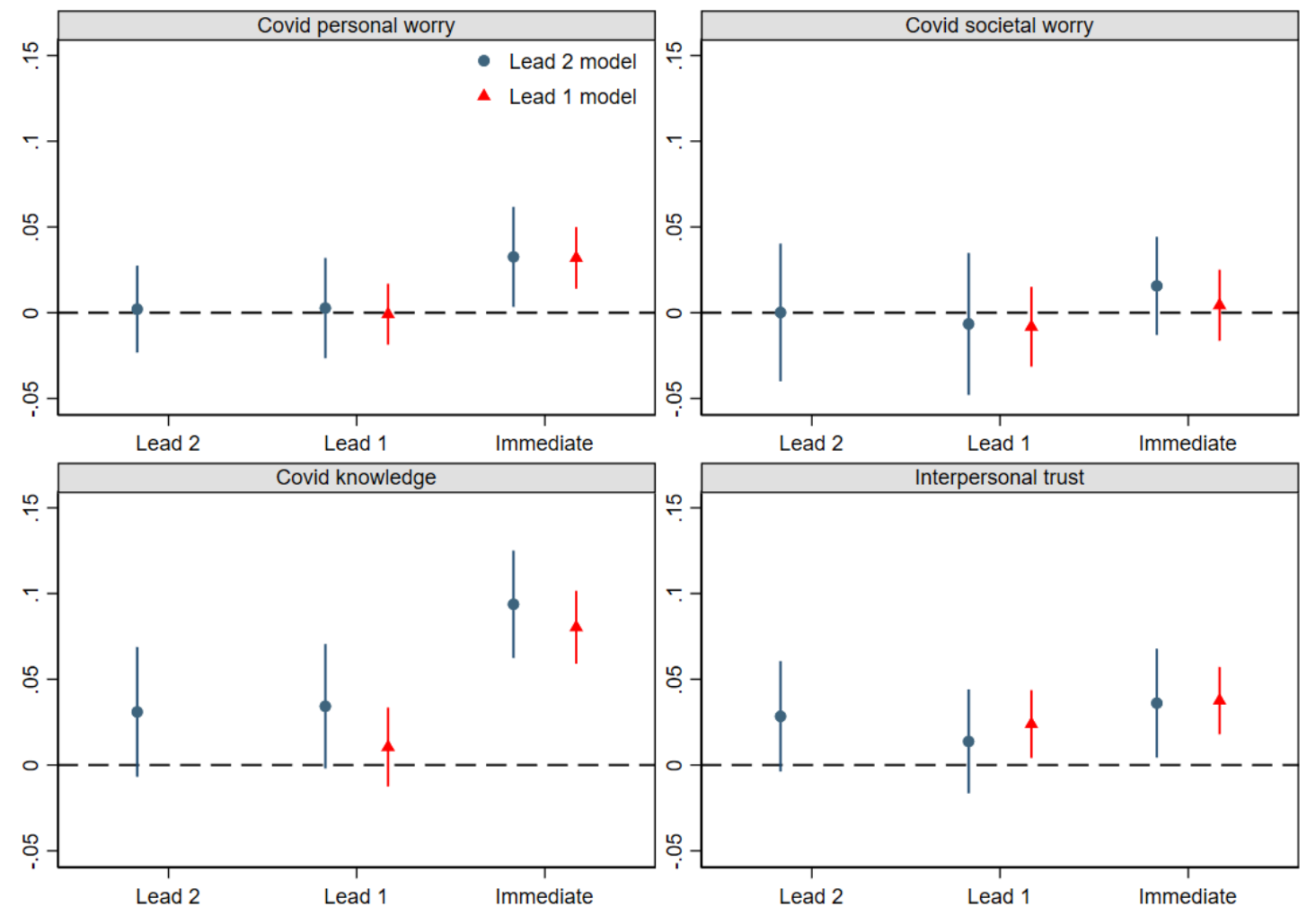

Note: Blue filled circles provide unstandardized regression coefficients from two-way fixed effects analyses. Standard errors are two-way clustered by individual and time. 95 and $90 \%$ confidence intervals. 


\section{C.2 Estimating the individual-level fixed effects, by country}

Figure OA9: Individual-level fixed effects, by country
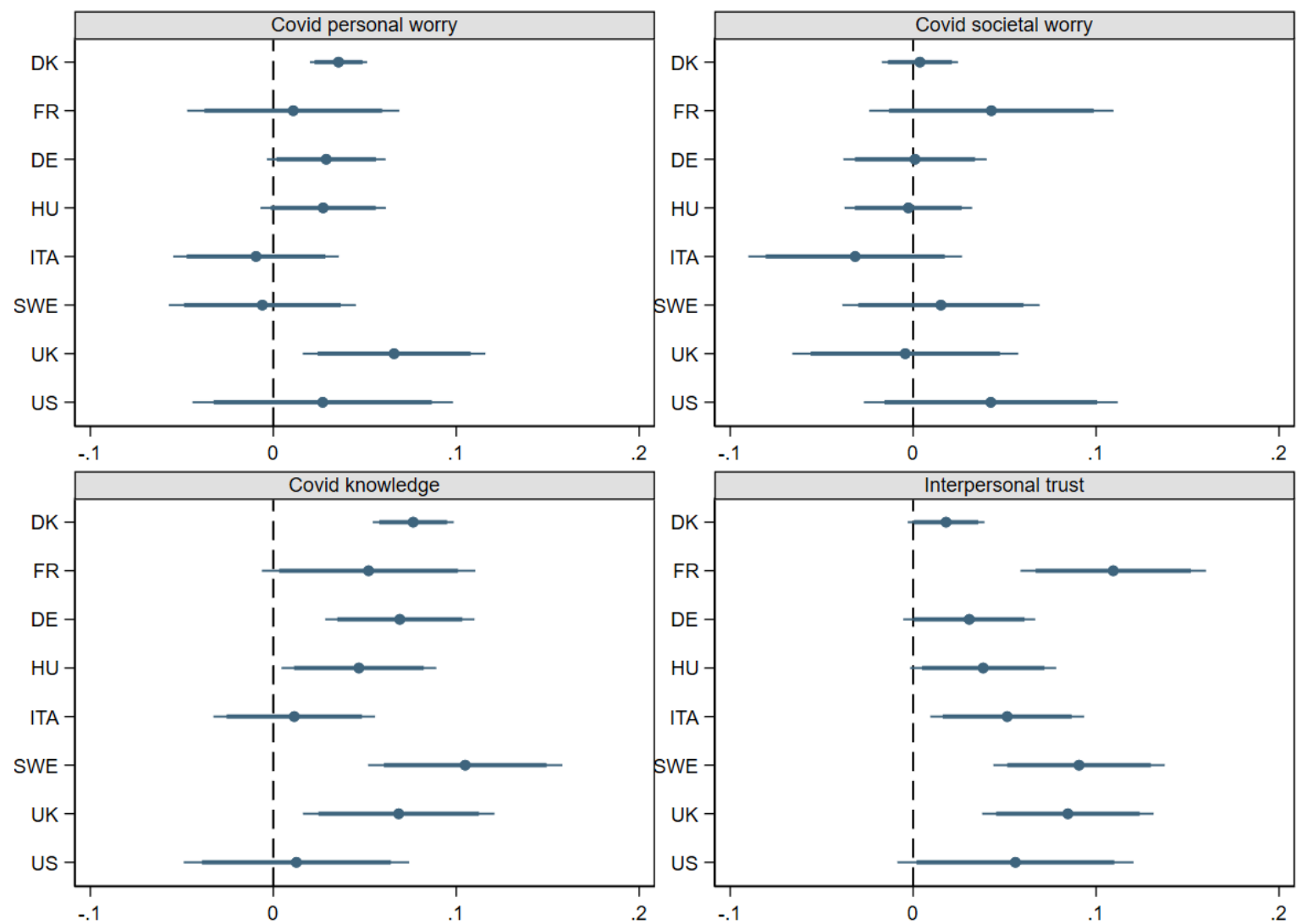

Note: Blue filled circles provide unstandardized regression coefficients from two-way fixed effects analyses. Standard errors are two-way clustered by individual and time. $95 \%$ confidence intervals. 


\section{Supporting Results: Country-level analyses}

\section{D.1 Estimating the country-level fixed effects, leads and lags}

In Figure OA10, we utilize the same two-way fixed effects estimator as above, but now we also include two leads and two lags into the models. Crucially, the estimated coefficients on the leads are close to 0 and far from conventional levels of statistical significance. Moreover, the estimated impacts of the immediate effects remain fundamentally unchanged upon control for the leads. In other words, this means that we do not observe an increase in support that precedes changes in the predictors. This corroborate the design-based identification and hence the causal interpretation of the estimated effects. The capture long-term impacts on support. The conclusions from these models are similar to those of column 3 in Table 3 . There is very little evidence that the predictors impact on support beyond its immediate effect.

Figure OA10: Within country variation, leads and lags

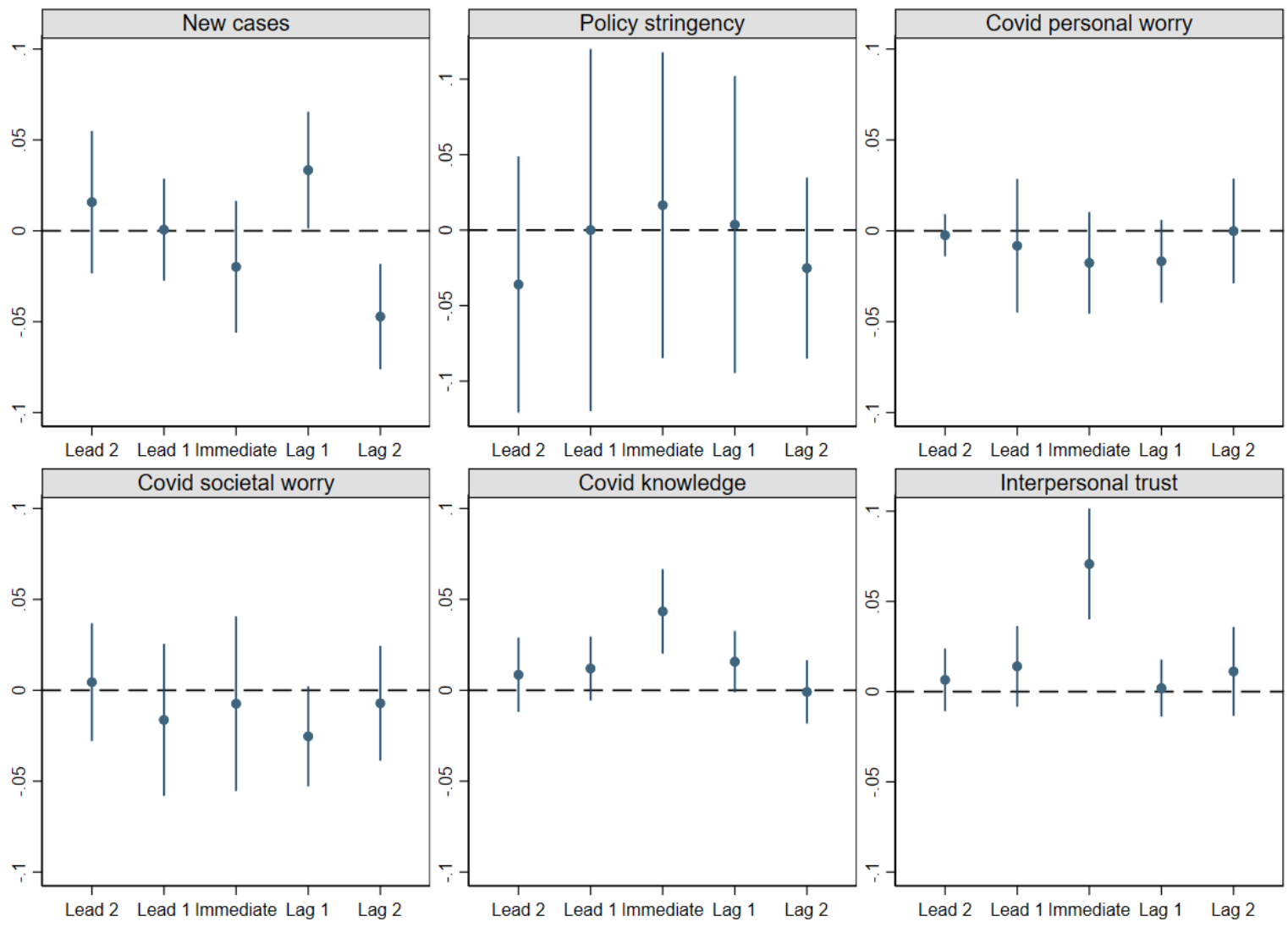

Note: Unstandardized regression coefficients. $95 \%$ confidence intervals. Standard errors are clustered by country. 


\section{D.2 Explaining aggregate differences in levels of support across countries}

In this section we seek to explain differences in the levels of support between countries. Therefore, we aggregate our data by country, averaging across all time periods. Figure OA11 displays the bivariate correlations between support and each of our predictors. It is important to note that these analyses are highly limited in terms of statistical power by the fact that they only include eight national cases. As an example, it makes little sense to move beyond the simple bivariate correlations displayed in Figure OA11 because of a high risk of overfitting the data, implying also that it limits our ability to control for other factors when running the analyses. With such limitations in mind, the analyses are nonetheless informative.

Figure OA11: Cross-country overall correlations
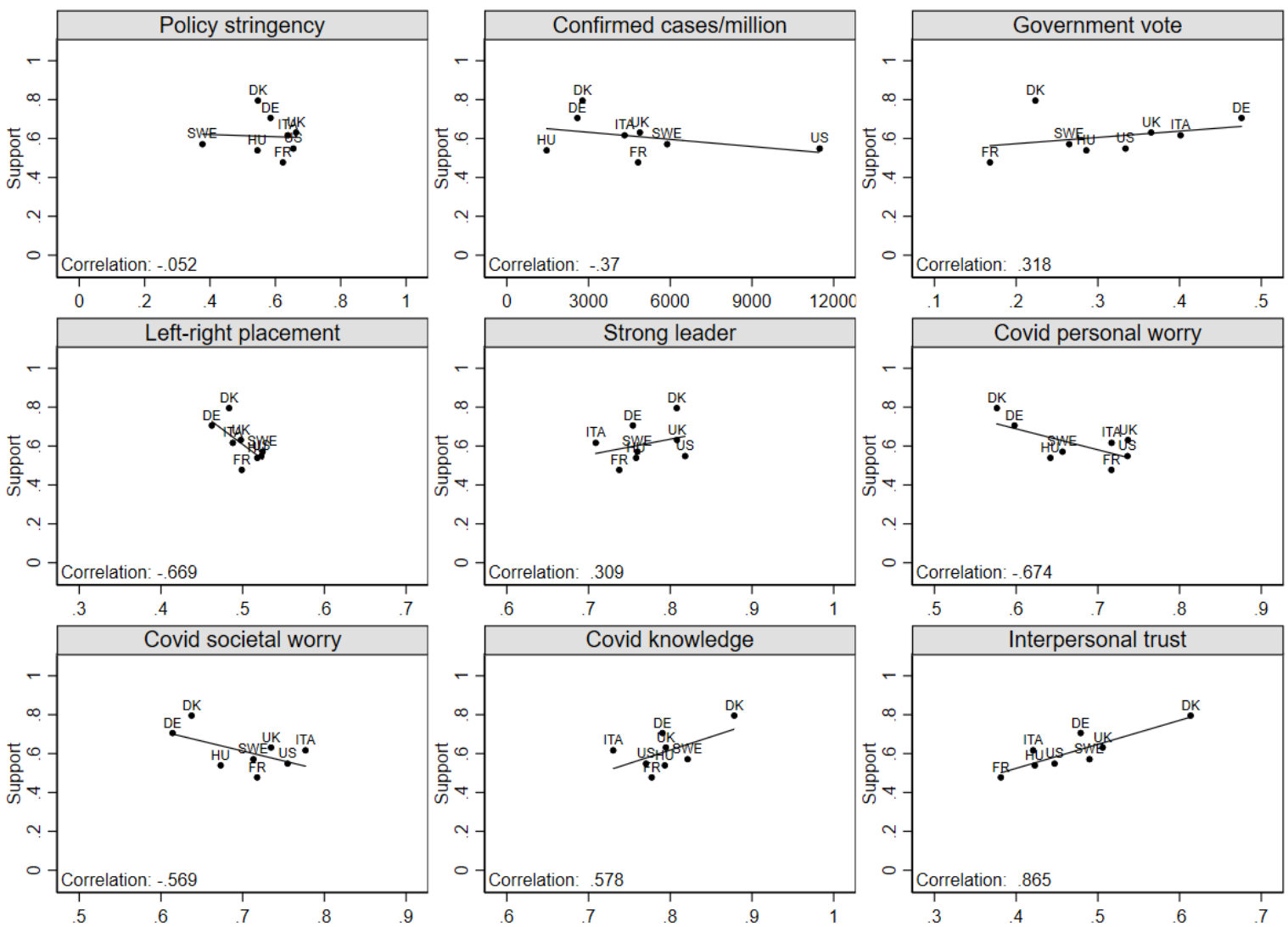

Note: Solid lines describe the linear relationship between aggregate levels of support and each of the correlates.

First, just as Figure 4, Figure OA11 shows that the level of support is relatively independent of both the level of policy stringency and the severity of the local epidemic. Second, for the political variables, we observe a relatively close fit between reporting that you voted for the prime minister's party at the last national first order election and support support for the response. 
However, Denmark is a notable outlier that exhibits low support for the government and high support for the response. This is likely explained by the political system with many parties and a relatively low share directly voting for the prime minister's party. Note that if Denmark is removed, the correlation amounts to 0.93 . Moving to the left-right placement scale, we observe a large negative correlation, implying that in countries with more right leaning populations we see more scepticism toward the response. Note, however, that there is quite little variation on the left-right scale across countries, making it difficult to assess the reliability of this result. Moreover, it is important to note that this results is difficult to interpret independently of the "color of the government". Focusing on the preference for a strong leader, we see a moderately positive association, but we large variability around the trend. Third, for both personal and societal worry, we observe negative correlations with support. Implying, that support is lower in countries characterized by higher levels of worry. Here, it is important to note that these association likely reflect a bias, where aggregate levels of worry is correlated with, for example, the country-specific epidemic development which likely also to correlates with support for the response. Finally, knowledge and trust are strongly positively associated with support with correlations of about 0.58 and 0.87 , respectively. Overall, interpersonal trust seems to be the most powerful predictor in explaining variations in levels of support across countries. In line with analyses above, this points to a classical crisis response, where prosocial motivations are crucial for people deal with crises. 